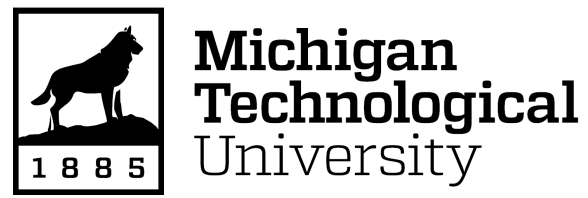

Michigan Technological University Digital Commons @ Michigan Tech

Dissertations, Master's Theses and Master's Reports

2021

\title{
AUGMENTED REALITY AS A TOOL FOR INDUSTRIAL HERITAGE EDUCATION AND INTERPRETATIONS
}

Garand A. Spikberg

Michigan Technological University, gaspikbe@mtu.edu

Copyright 2021 Garand A. Spikberg

\section{Recommended Citation}

Spikberg, Garand A., "AUGMENTED REALITY AS A TOOL FOR INDUSTRIAL HERITAGE EDUCATION AND INTERPRETATIONS", Open Access Master's Report, Michigan Technological University, 2021.

https://doi.org/10.37099/mtu.dc.etdr/1317

Follow this and additional works at: https://digitalcommons.mtu.edu/etdr

Part of the Archaeological Anthropology Commons, and the Science and Technology Studies Commons 


\title{
AUGMENTED REALITY AS A TOOL FOR INDUSTRIAL HERITAGE EDUCATION AND INTERPRETATIONS
}

\author{
By
}

Garand Spikberg

\begin{abstract}
A REPORT
Submitted in partial fulfillment of the requirements for the degree of MASTER OF SCIENCE

In Industrial Heritage and Archaeology
\end{abstract}

MICHIGAN TECHNOLOGICAL UNIVERSITY

2021

(C) 2021 Garand Spikberg 
This report has been approved in partial fulfillment of the requirements for the Degree of MASTER OF SCIENCE in Industrial Heritage and Archaeology.

Report Advisor: Donald Lafreniere

Committee Member: Sarah Scarlett

Committee Member: Richelle Winkler

Department Chair: Donald Lafreniere 


\section{Table of Contents}

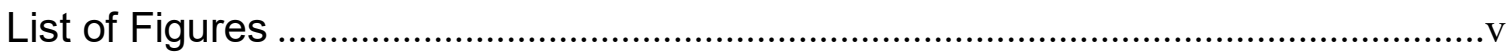

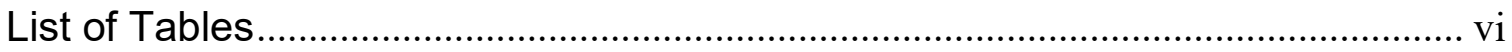

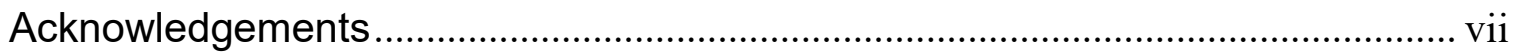

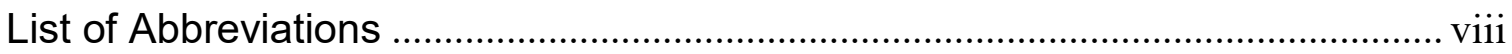

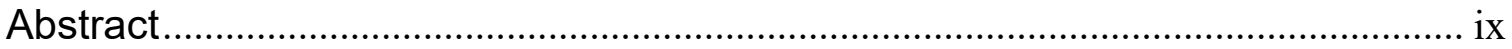

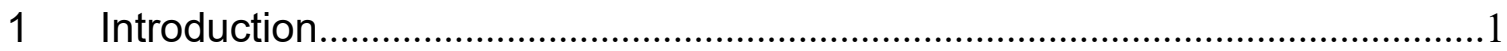

1.1 Case Study: Champion Mine …………………....................................

1.2 The Intersection of Heritage and Historical GIS ……...............................

1.3 The Potential for Augmented Reality to Improve HSDIs .........................8

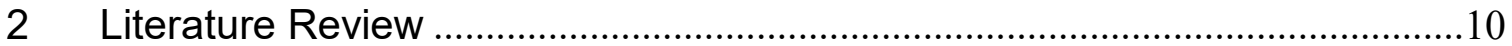

2.1 Digital Tools for Heritage ....................................................................... 11

2.2 Historical GIS and Historical Spatial Data Infrastructures......................13

2.3 Augmented Reality ..............................................................................17

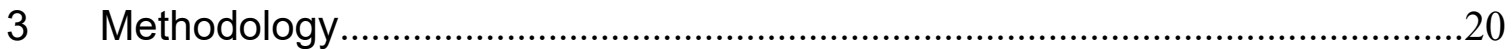

3.1 An Augmented Reality Application for Supporting Industrial Heritage Interpretation and Education .........................................................................21

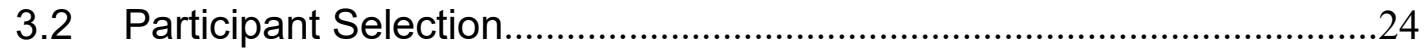

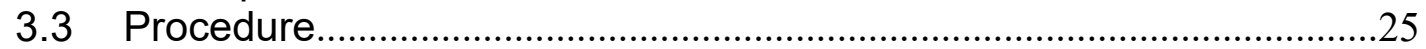

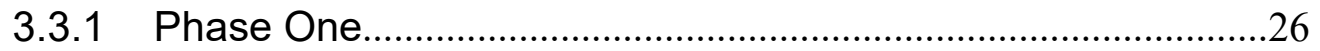

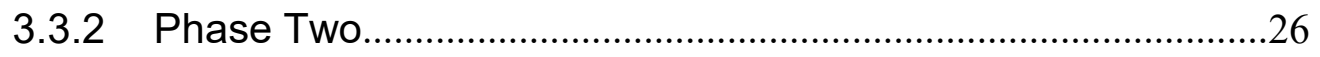

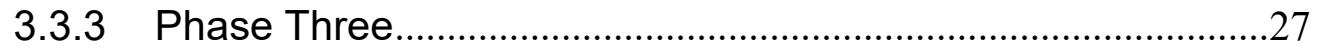

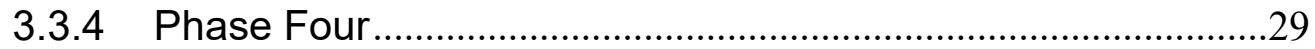

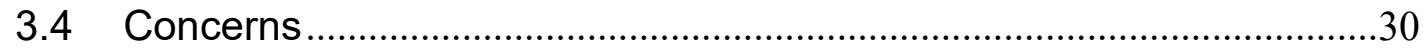

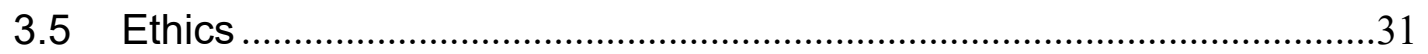

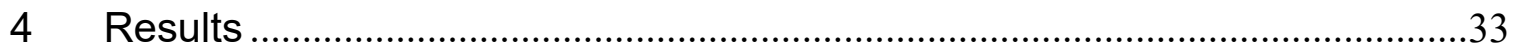

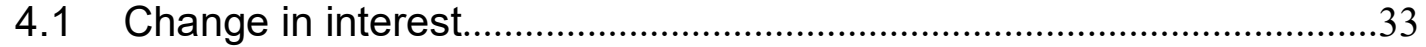

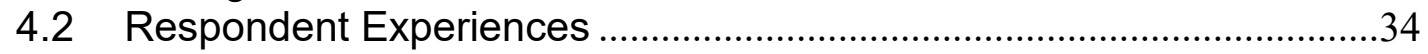

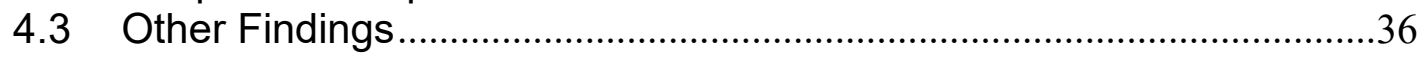

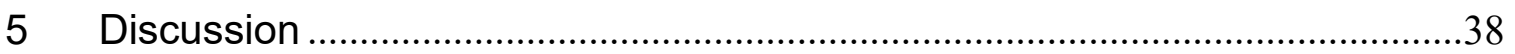

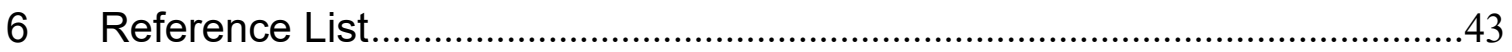

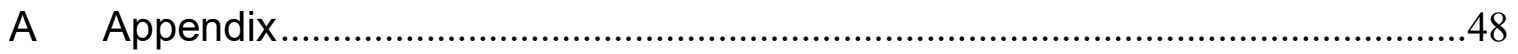

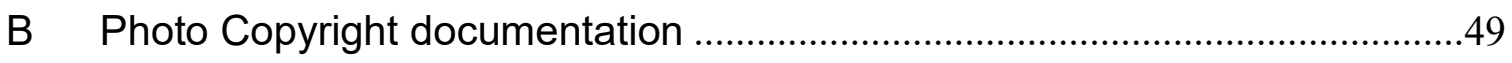




\section{List of Figures}

Figure 1: Champion Mine is located in Painesdale Michigan roughly 8 miles South West of Michigan Technological University

Figure 2: Accessing the MTU Single Sign On System..........................................21

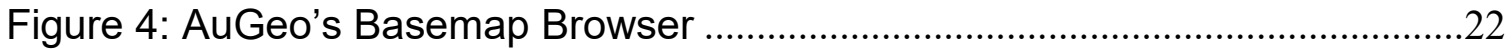

Figure 3: A Point Containing an Archival Photograph of the Champion Mine Shaft

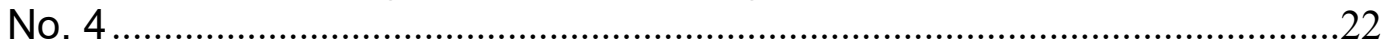

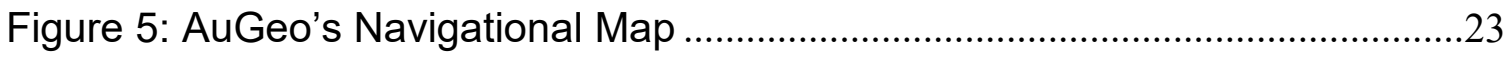

Figure 6: Briefing the Participants Before the Exploration........................................27

Figure 7: Participant Using the Application in the Shaft House ...............................27

Figure 8: Participants Discussing Data From the Hoist House...............................28

Figure 9: Participants Viewing the Landscape Through the App ..........................28

Figure 10: Examples of Positive Experiences..........................................................

Figure 11: An Example of a Mixed Experience …………....................................35

Figure 12: Examples of Negative Experiences …………………….....................35

Figure 14: Examples of Responses Stating the App Aided in Navigation ..............36

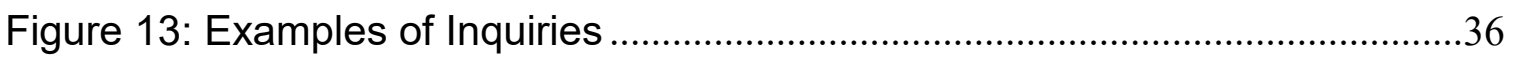




\section{List of Tables}

Table 1: Description of Participant Change in Interest...................................... 33

Table 2: Participant Experiences and Expectations....................................... 34 


\section{Acknowledgements}

First and foremost, I want to thank the team at the Keweenaw Time Traveler and Michigan Tech Geospatial Research Facility, particularly Daniel Trepal and Michael Madison, their support and friendship throughout this process meant the world to me. My cohort in the Industrial Heritage and Archaeology program, particularly Andrew Anklam and Timothy Maze for their assistance in my initial drafts. All of my friends made during my undergraduate degree who have continued to support me in this endeavor. Finally, my advisor Don Lafreniere for all his help in helping to develop my skills as a researcher, student, and writer. 


\section{List of Abbreviations}

- KeTT: Keweenaw Time Traveler

- NPS: National Park Service

- KNHP: Keweenaw National Historic Park

- GIS: Geographical Information Systems

- HGIS: Historical Geographical Information Systems

- HSDI: Historical Spatial Data Infrastructure

- CCHSDI: Copper Country Historical Spatial Data Infrastructure

- CLIR: Council on Library and Information Resources

- AR: Augmented Reality

- VR: Virtual Reality

- HUD: Head(s) Up Display

- QR Codes: Quick Response Codes

- SSO: Single Sign On 


\section{Abstract}

Combining Augmented Reality with spatially and temporally robust Historical Spatial Data Infrastructures may have the potential to provide users with interpretive and educational opportunities they otherwise would not have. Adapting research oriented historical GIS projects such as the Copper Country Historical Spatial Data Infrastructure to usage as interpretive material through the utilization of "off the shelf" augmented reality applications such as AuGeo has the potential to expand the utility and reach of that research data outside of the lab, while providing new interpretive opportunities by allowing users to see that data in its original spatial context and giving them the freedom to explore it in their own way. 


\section{Introduction}

Interpreting the past has always come with as many caveats and pitfalls as it has triumphs; records are left incomplete, landscapes lose their most valuable features to time and neglect, lived experiences go undocumented. Industrial heritage in particular feels these and other pressures; with landscapes yielding to redevelopment or requiring remediation, populations dispersing after industrial activity ceases, while the communities that remain are often plagued by economic and social instability. Fortunately, heritage interpreters have developed tools and techniques to tackle these challenges. Local museums/heritage groups work to maintain connections to the past through developing interpretive information such as placards, pamphlets, leading walking tours, conducting re-enactments, etc. Those heritage organizations maintain the responsibility of distributing that interpretive material throughout the landscape to account for things like missing structures or historical context. Maps have long been used as interpretive tools, providing visitors and users with graphical representations of the spaces they are interpreting. Maps have additional utility when layered together from different time periods, interpretive institutions use layered map exhibits to show the changes to the built environment of a site over time, producing graphical representations of larger segments of the past.

Others have already begun to explore the utility of Augmented Reality as another interpretive and educational tool on the belt of heritage professionals by 
allowing users to explore heritage sites through the lenses of their smartphones where interpretive material is otherwise unavailable (Cushing \& Cowan 2017, Kaplan \& Shiff 2017, LeMire 2018, Davies 2014, Ellenberger 2017). However, few studies have been concerned with the intersection between Historical Geographic Information Systems/Historical Spatial Data Infrastructures (HGIS/HSDI) and AR, leaving a natural gap for this study to attempt to fill while simultaneously attempting to address the needs of local heritage professionals of the Painesdale Mine and Shaft Inc at the Champion Mine in Painesdale Michigan. This study used to attempts to fill that gap by asking how can the integration of Augmented Reality technologies with Historical Spatial Data Infrastructures support industrial heritage interpretation and education? 


\subsection{Case Study: Champion Mine}

The "Champion Mine" largely refers to the Number 4 shaft house site in Painesdale Michigan, originally constructed in 1902 it is largely known for being the oldest still standing shaft house in the "Copper Country". Major surviving structures at the site include the shaft house, the hoist house, the mine Captain's

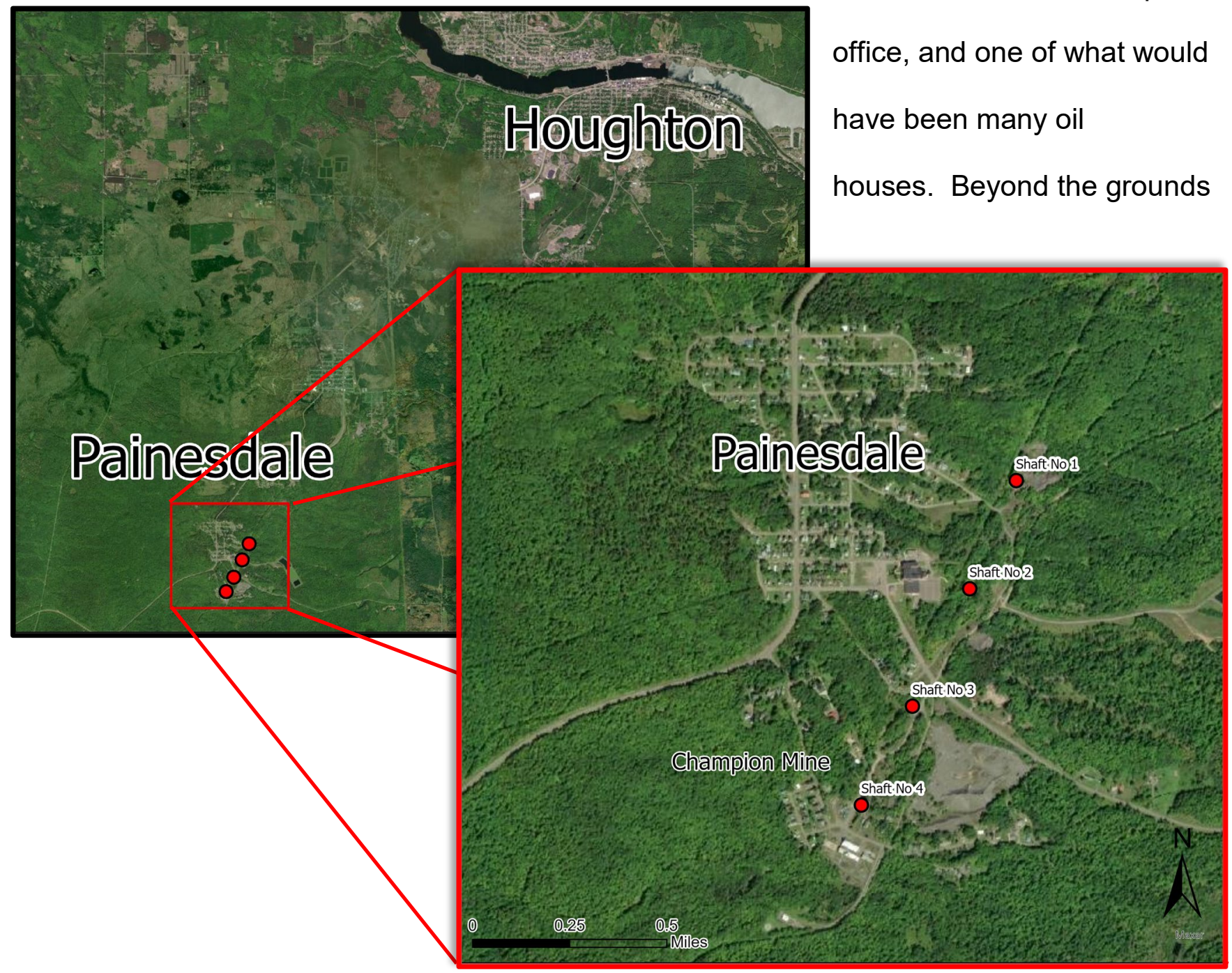

Figure 1: Champion Mine is located in Painesdale Michigan roughly 8 miles South West of Michigan Technological University

owned by the Painesdale Mine and Shaft corporation are repurposed machinist shops and housing formerly devoted to company employees. While the surviving shaft house was constructed in 1902, the Champion Mine itself was established 
in 1889, and consisted of 4 shafts running at intervals from Atlantic Mine to Painesdale. As a result, the site itself represents only a small fraction of what would have been a part of the industrial landscape while in operation. The Copper Range Company operated the mines until 1967, through various trials and tribulations such as two world wars, and worker strikes. Painesdale Mine and Shaft Inc. has become more active in recent years, coordinating volunteer work events and digitizing the site's vast records collection. However, they operate under very limited resources, the majority of which go towards stabilizing and maintaining the site. To date, Painesdale Mine and Shaft Inc maintains a small amount of interpretive paneling and provides weekly guided tours of the site, with plans to develop more interpretive materials through collaborative efforts with students at Michigan Technological University to accommodate visitors outside of their relatively narrow availability.

Continuing this trend through the development of an Augmented Reality heritage application is a perfect opportunity to not only continue to evaluate AR as tool, but to nurture the collaborative relationships that are so important in this field. The Number 4 shaft house represents an important example of the Copper Country's surviving mining and industrial sites, which are rapidly becoming major attractions for heritage tourism. This situation presents an opportunity for heritage researchers within academia to collaborate with local heritage organizations to develop interpretive materials and programs for those sites to better support their communities. 


\subsection{The Intersection of Heritage and Historical GIS}

In 2015, Lafreniere, led an interdisciplinary team including this author, to further expanded on the concept now known as a "Historical Spatial Data Infrastructure". The idea was to create a regionalized "space-time linked digital archive" capable of answering questions posed about the development of systems, geographic scale, accessibility and expandability (Trepal, Lafreniere \& Gilliland 2020). This project has come to be called the Copper Country Historical Spatial Data Infrastructure or CC-HSDI, as its extent covers the major population centers of the Keweenaw Peninsula from roughly 1880-1950, a period chosen for its significance in the rise, peak, and decline of the area's mining activity. The term "Copper Country" has come to colloquially represent most of Michigan's Upper Peninsula's Keweenaw Peninsula. The area's unique geography led to unusual deposits of pure copper, some single pieces weighing multiple tons. The unusual nature of the copper deposits being mined coupled with the intense period of industrialization led to the nickname for the area.

The CC-HSDI contains hundreds of thousands of spatialized records from Polk city directories and the US census, digitized Sanborn Fire Insurance Plans providing highly detailed representations of the built environment, geographically linked school attendance records and business directories, as well as hundreds of "Stories" submitted by users of the CC-HSDl's public interface known as the Keweenaw Time Traveler (KeTT). In the coming year, the CC-HSDI will also incorporate the full set of employee records from the Calumet and Hecla Mining 
Company and the mapped full count decennial census. As the public interface, KeTT is often marketed as a sort of "Google Maps" for the Keweenaw's history, however the approach is more akin to "deep mapping" (Ridge, Lafreniere \& Nesbit 2013). Meaning, it provides access to a robust temporal depth of information not readily available on something like Google Maps. These differences are key because all those interlinked and overlaid data sources are what starts to give users the ability to develop their own deeper interpretations of the postindustrial landscape of the Keweenaw. The historical spatial data present within the CC-HSDI represents more than just some arbitrary representation of the past. These datasets come from primary sources and documents that served their communities for years, whether it's employee cards marked with decades of service to mining companies or Sanborn Fire Insurance Plans updated with hand-written notes and annotations indicating new construction or buildings lost to fire, all of these sources work together as true pieces of industrial heritage together. While none of these sources are perfect on their own and have their own drawbacks, biases, and gaps, they are an essential step in truly trying to represent the past.

On the more scholarly side, the CC-HSDI has already been utilized in a number of research projects and dissertations, studies have been conducted on public schools as vectors for disease transmission (Lafreniere et al 2021), accumulated industrial pollutants and their potential impacts on children's health (Stone et al 2019), public participatory GIS (Lafreniere et al 2019), industrial and 
public archaeology (Trepal, Lafreniere \& Stone 2021; Trepal, Lafreniere \& Gilliland 2020; Trepal, Scarlett \& Lafreniere 2019), historical education (Scarlett et. al 2019), and 3D procedural modelling of landscape change over time (Arnold \& Lafreniere 2018). Future research is planned in studying the migration experience of French Canadians and their associated socio-economic mobility while they occupied the Keweenaw. Overall in-and-out migration patterns for the region during the periods of rapid industrialization and deindustrialization; potentially identifying trends in where miners came from, where they went, and what they did after copper mining. All in the effort of connecting the lived experiences in the Keweenaw to the greater narrative of the industrial Midwest.

Even with this body of scholarly work attributed to the CC-HSDI, the Keweenaw Time Traveler is not perfect. One of the longest acknowledged drawbacks of KeTT in its current iteration is that it's built for desktop browsers and does not support geolocation services within its proprietary interface. This presents a significant roadblock to attempting to use KeTT in the field, preventing users from establishing a real sense of place especially if they aren't familiar enough with the area to know where they are on the map. In fact, in the past when tours have been given using data from the CC-HSDI, a separate interface with geolocation has been used and mocked up to represent the future planned "mobile" version of KeTT (Scarlett et al 2019). The lack of true on-site interaction with these data sources in the field leaves a significant gap in the capabilities of the Time Traveler and by extension the CC-HSDI. The availability of this data 
infrastructure and current limitations of the methods to interact with it create the perfect space in which to develop a mobile application using geolocation functionality. This is supported by the fact that mobile devices are already the dominant way in which people interact with Augmented Reality applications, making a mobile application the perfect way to augment the potential for interpretations developed by visitors to sites such as the Keweenaw National Historic Park (KNHP).

\subsection{The Potential for Augmented Reality to Improve HSDIs}

Using Augmented Reality (AR) applications as a platform to harness the power of a historical spatial data infrastructure can help to open the door to new experiences and opportunities for heritage interpreters and visitors to explore the complexities of industrial landscapes while complementing the limitations of things like curated walking tours. Cushing and Cowan identified the need to provide data from primarily research institutions such as museums, archives and libraries to non-researchers to allow them develop their own uses and interpretations with that data (Cushing \& Cowan, 2017). They developed an AR walking tour as an attempt to address this shortfall called Walk1916. The application used spatially distributed photographs and narratives, sourced from local research institutions, to recreate some of the historical context of the 1916 Easter Rising, largely associated with the beginning of the Irish independence movement (Cushing \& Cowan, 2017). Users were presented with a map 
showing the locations the photographs represented, and directed to walk towards them as they saw fit, where they would be presented with a viewfinder to overlay the photos onto their device's camera, attempting to place the users in the same location where the photographs were taken. This approach demonstrated the potential for utilizing these kinds of resources outside of the institutions that house them, users commented on the positive effect of being able to contrast the historical images with their modern spatial context (Cushing \& Cowan, 2017). Cushing and Cowan's results highlight the need to provide institutional research data to non-researchers, to support a broader interpretation of heritage landscapes by democratizing data broadly to permit unexpected new applications for that data. This report outlines an attempt to demonstrate the utility of the CCHSDI combined with Augmented reality in supporting heritage education and interpretation efforts at the Champion mine site and encouraging the democratization of that same research data for heritage interpretation. With particular interest in addressing known shortfalls of establishing a sense of place that the CC-HSDI currently suffers from. The question is, how the integration of augmented reality technologies with the spatio-temporally robust Historical Spatial Data Infrastructures can support industrial heritage interpretation and education? 


\section{Literature Review}

In order to establish the academic framework from which this study is derived, there are three main areas of literature that need to be considered; Digital Tools for Heritage, Historical Geographic Information Systems (HGIS), and Augmented Reality (AR). Many areas of digital heritage applicable to this report found early progress in the 1990s largely in digitizing existing archival collections at the university level (Stephenson 1999, Besser 1997). Collaborative efforts to provide online access to digital surrogates of cultural heritage materials can be found beginning in 1995, the Museum Educational Site Licensing Project brought together seven universities and cultural heritage repositories to digitally catalog over 10,000 images for use at participating universities (Stephenson 1999). Landsat imagery was being used for vegetation and land usage analysis by 1997 , with references to work even earlier in the decade, though that work was primarily for studying vegetation (Driese et al 1997). The fact that this kind of early application for GIS technologies wasn't used for heritage work highlights how the field of historical geography needed to adapt those technologies to suit the needs of historians (Holdsworth 2002, Holdsworth 2003). While methods for creating virtual recreations of cultural heritage sites were being developed by 1997 (Marini et al 1997). Though largely limited to world heritage sites with cutting edge resources for the time, in this case the modelling process was developed for use on the Colosseum. What follows is a brief history of each field as well as related works this study drew influence from. 


\subsection{Digital Tools for Heritage}

Early digital heritage efforts largely seem to be centered around online access for existing heritage datasets at institutions such as universities and archives (Stephenson 1999, Besser 1997). Earlier efforts to digitize anything beyond plain text ran into the fact that good quality images were too expensive to store digitally due to the technology at the time (Besser 1997). In 1997 the National Park Service began making Historic American Buildings Survey (HABS) records available to access online with the commitment to continue to add material as it was collected. This trend of providing digital access to physical resources continues into the mid-2000s though with scholars calling for a standardized methodology for digitizing and displaying archival catalogs (Quintero \& Addison 2008). This suggests that at the time, the digitization of archival "back catalogs" had yet to reach academic maturity. The Council on Library and Information Resources (CLIR) is an organization committed to continuing to support digitization and access efforts, since 2008 CLIR has been funding projects to catalog and digitize "hidden" collections of archival data. CLIR has even contributed to some of the efforts of the Keweenaw Time Traveler with a grant to fund the transcription and digitization of employee record cards from the Calumet and Hecla Mining company located in the Michigan Tech Archives; this grant also supports their integration into the CCHSDI.

"Digital heritage tools" begin to include more than just archival information in the later half of the 2000s, in particular one starts to see a trend in more 
diverse digital documentation tools such as laser scanning, photogrammetry, total stations, and other digital data collection tools; with these the question of how to most effectively integrate these tools into the more traditional documentation process became a pressing one (Quintero Blake \& Eppich 2007). While full virtual recreations of physical structures existed before this time, they were largely limited to cutting edge projects on major world heritage sites such as the Colosseum in Rome (Marini et al 1997). With wider availability of tools such as 3D LiDAR scanning, digital modelling programs, computers capable of rendering 3D graphics, it becomes much more important for documentation efforts to include and standardize approaches to using these digital documentation tools and apply them across the larger fields of heritage preservation and interpretation (Quintero Blake \& Eppich 2007).

While digital documentation of the built environment continued to develop into the 2010s, a larger change started to emerge in the idea of the digital as heritage which almost became intertwined with the usage of digital tools for heritage (Mezzino et al 2017). The 2010s saw the critical point of social media becoming the dominant driver of traffic on the internet, and a number of heritage fields have capitalized on this to start to utilize social media for heritage efforts (Jailot et al 2020, Casimiro 2019). Some have described this approach as a way to attempt to crowdsource heritage data such as photographs, personal stories and even things like oral histories (Jailot et al 2020). Casimiro suggests that this kind of approach may help to relieve some of the shortcomings of HGIS that date 
as far back as its roots in historical geography when it comes to collecting and analyzing qualitative data (Casimiro 2010). In much the same way, others have argued that public participation in heritage research could lead to deeper understandings of how communities wish to interact with their heritage to help shape our efforts as heritage researchers towards the kind heritage communities want to engage with (Lafreniere et al 2019).

Within the field of HGIS this approach is known as "Public Participatory" GIS. By the end of the 2010 s and into the 2020 s digital heritage has embraced a pedagogy that recognizes emerging technologies will continue to provide new opportunities for not only answering cultural heritage questions, but in finding new questions to ask (Southall \& Lafreniere 2019). Whether those questions require extensive social media campaigns, complex database and network analysis (Parrinello \& Cioli 2019; Kreutel 2019), full virtual reconstructions of historic landscapes (Barceló et al 2019, Arnold \& Lafreniere 2018), and more; it isn't necessarily important for the researchers to use every tool at their disposal, but to recognize that new tools in digital heritage are being developed faster than ever before (Kermers 2020).

\subsection{Historical GIS and Historical Spatial Data Infrastructures}

Because the key datasets that this study utilized largely fall under the umbrella of historical GIS, it's important to consider the history of the field. It is particularly important to acknowledge that HGIS not only draws from the technical and analytical experience in the fields of GIS, but also draws from the 
theoretical and pedagogical framework of the schools of historical geography (Holdsworth 2002, Holdsworth 2003). Historical GIS, while present throughout most of the 1990s, largely remained limited to the visualization of populations at larger scales such as counties or parishes (Gregory et al 2002). The North American Population Project attempts to record link census microdata from both North America and Europe to provide opportunities for analysis at a scale far beyond what had been previously attempted (Ruggles et al 2011). As HGIS grew in its maturity in the early 2010 s, scholars began to utilize the spatial analytical capabilities for studies on topics such as urban change (Sadler Gilliland \& Arku 2011, Novak \& Gilliland 2016), housing discrimination/segregation (Gilliland Olson \& Gauvreau 2011, Tuckel Schlichting \& Maisel 2007, Salder \& Lafreniere 2017), mapping historical pandemics (Kennedy et al 2015, Lafreniere et al 2021). This interest in HGIS benefited from the 'spatial turn' in history (Withers 2009) and was largely facilitated by the establishment of common workarounds to circumvent the limited temporal extent of GIS software designed for use by municipalities rather than academia (Gregory Kemp \& Morsten 2001, Knowles 2005). While these early approaches yielded methodological and technological insights beyond just the results of their studies, they were not without their own limitations.

On its developmental pathway the field of HGIS needed to adapt and find ways to overcome many shortcomings of both analytical approaches and GIS technology itself; the inadequacy of boundary data to truly represent the extent of human spaces, the limitations of displaying the temporal extent of features within 
GIS software, and the incomplete picture that historical records often leave us with (Knowles 2005, Knowles 2015). Lock reiterates the persistence of these shortcomings into the 2010 s, with a specific focus on the inability to present scale, both physical and temporal, in a way that is meaningful to those outside of the discipline of HGIS (Lock 2010, Lock \& Pouncett 2017). While historians are acutely aware of the incomplete nature of the historical record, others have taken the opportunity to attempt to address these shortcomings in various ways.

One particular school of thought stems from Sherry Olson's work mapping a number of surnames across Montreal combining a number of different data sources across a large temporal extent from 1840 - 1900 (Olson \& Thornton 2011). Later Lafreniere and Gilliland would build on all of these ideas in their "Imag(in)ing London Historical GIS Project" mapping both the built and social environments of London Ontario from 1871-2013 (Lafreniere \& Gilliland 2015). This London HGIS demonstrated the potential that came with building a dataset not with the intent to address a specific research question, but to serve as a flexible framework to allow for the pursuit of a plethora of data-driven inquiries into subjects such as historical spaces, populations and social processes.

Since the CC-HSDI is the successor project to Imag(in)ing London, it differs from that project in two notable ways. The first way the CC-HSDI has advanced the HSDI approach is through its spatio-temporal linkages; linking 
structures, business, people, and more across time. These robust spatiotemporal linkages allow for the study of any number of aspects of how communities change over time rather than how they existed just at one point (Arnold \& Lafreniere 2018, Arnold \& Lafreniere 2017, Trepal Scarlett \& Lafreniere 2019). The second advancement made by the CC-HSDI is through its incorporation of public engagement; with funding awarded from the National Endowment for the Humanities a public interface was developed and launched as the Keweenaw Time Traveler (KeTT). KeTT not only allows members of the public to view query and share data from the CC-HSDI, but to contribute to it through digitizing information about the built environment from historical maps and through submitting their own stories personal stories and images to enrich and personally contextualize this data infrastructure (Scarlett et al 2018, Lafreniere et al 2019). The CC-HSDI sits at the apex of decades of development in HGIS, particularly in regards to its ability to facilitate "Deep Mapping" through spatio-temporal linkages and its robust catalog of data resources (Ridge Lafreniere \& Nesbit 2013, Arnold \& Lafreniere 2018, Arnold \& Lafreniere 2017,Trepal Scarlett \& Lafreniere 2019). It is important to note however, that this study is not fully utilizing the full potential of the CC-HSDI and is not doing any sort of "Deep Mapping". This is due to the fact that the study site at Champion Mine has a limited amount of data available for it, nearly entirely lacking any of the temporal linkages that facilitate deep mapping. 
The push for public engagement with the Keweenaw Time Traveler, and by extension the CC-HSDI provides an important link between the research based spatial data, and the call for data democratization from Cushing and Cowan. Beyond pre-existing efforts, more can be done to facilitate public engagement with this research infrastructure in a way that directly ties a general audience to a sense of place. Combining the spatial, temporal, and big historical data of the CC-HSDI with some of the AR approaches detailed in the next section is potentially one way to begin to explore the benefits of such an approach.

\subsection{Augmented Reality}

Ultimately the examples that follow only demonstrate a small sample of the work that has gone into finding novel uses for Augmented Reality technology, but still provide a solid foundation from which to start exploring the subject. Augmented Reality is an enhancement of the real world using digital tools to provide extra information to the user, providing a natural point of synergy with the kinds of spatialized data inherent in HGIS. This data driven enhancement can be done using digital displays, audio information, tactile feedback, or other means of sensory input. While digital display via smartphones is the standard of today, the first 'true' digital augmented reality display was developed at the University of Utah in 1968. It was only capable of displaying simple wireframe shapes within the confines of a single room, and required an apparatus that connected to both the user's head and the ceiling, as well as a room sized computer to generate the graphics (Sutherland 1968). In this context 'true' denotes that the head mounted 
display (HMD) in question displayed its images to both of the user's eyes, and was actually able to display information within a depth of field and enhanced the user's knowledge of a space, in this instance displaying symbols denoting the cardinal directions on walls of the testing room (Sutherland 1968). HMDs have largely fallen out of favor for consumer grade AR applications due to the relative ubiquity of smartphones, though some dedicated displays continue to be developed largely to suit the enterprise market, devices such as Google Glass and Microsoft Hololens. Systems designed for specific vehicles in the form of heads up displays (HUD) continue to show up occasionally in the consumer market, and are fairly common in military applications, particularly in avionics ( $\mathrm{Li}$ et al 2013, Gill 2020). In the medical field AR has been tested for education to assist in training students on examining patients (Von Jan et al 2012), clinical trials have been run using real time imaging to augment surgical procedures (Heide et al 2018), and Hololens has been tested in conjunction with ultrasound to function as AR imaging (Nusheene \& Bhupathy 2020).

Because of their relative ubiquity, smartphones have become the dominant platform for Augmented Reality applications and development, particularly so when it comes to educational and heritage focused applications. For example, Quick Response codes (QR codes) have been used to develop walking tours and disperse interpretive information (LeMire 2018, Davies 2014), while geolocation functions in smartphones have been used in tandem with GIS tools to create tours of historical events such as the Walk1916 
app mentioned earlier (Cushing \& Cowan 2017). At the higher end it is possible to project full 3D representations of individual structures or more onto landscapes, providing users with a sense of place for structures that are not present. One example of this was a project done by Louis Kaplan and Melissa Shiff, they used geolocated 3D models to create a proposed Jewish settlement on Grand Island in New York, allowing users to physically navigate the space and see what may have been (Kaplan \& Shiff 2017). There continue to be calls for further testing and development of new ways of incorporating AR into heritage and education (Ellenberger 2017). Few have attempted to combine AR with HGIS to date, let alone an HSDI as robust as the CC-HSDI. The potential here is to push the boundaries of what those two technologies might be capable of, and potentially further our understanding of how those technologies can be used to support and nurture the heritage interpretations of the public. 


\section{Methodology}

Going into this study it was important to identify what needed to be learned in order to determine how the augmented reality experience using AuGeo described earlier could be used answer the original research question. How can the integration of augmented reality with HSDIs support industrial heritage interpretation and education? As a result, this study was designed to focus on how the application changed participant's overall interest in industrial heritage, how it impacted the way participants explored the site, how their interpretations were shaped by both the app and the physical site, as well as identifying interpretations and inquiries they had after the study period. Data collection consisted of a survey sent to the participants before the study and a second more robust survey administered after the study. The pre-survey was meant to determine beginning interest and experience with the use of Augmented Reality while setting a baseline for participant interest in industrial heritage. After the pre-survey was administered, participants were transported out to the site (some chose to provide their own transportation) where they were given minimal prompting to then use the AR application to explore the site using the AR application. The post-study survey was designed to identify key areas of interest from the study site either digital or physical, to gather insights into participant's interpretations of the site, determine what participants valued about the experience, and to evaluate any sort of change in interest in industrial heritage. 


\subsection{An Augmented Reality Application for Supporting Industrial Heritage Interpretation and Education}

Before evaluating how the integration of Augmented Reality technologies with Historical Spatial Data Infrastructures can support industrial heritage interpretation and education an application is needed to actually perform that evaluation. For this study a custom application was intended to be developed, but was unable to be completed and published in time to be used for the study.

In response to that setback the application AuGeo was selected. It was a natural selection because the custom application was based on the source code of AuGeo, the only main difference between the two is that the custom

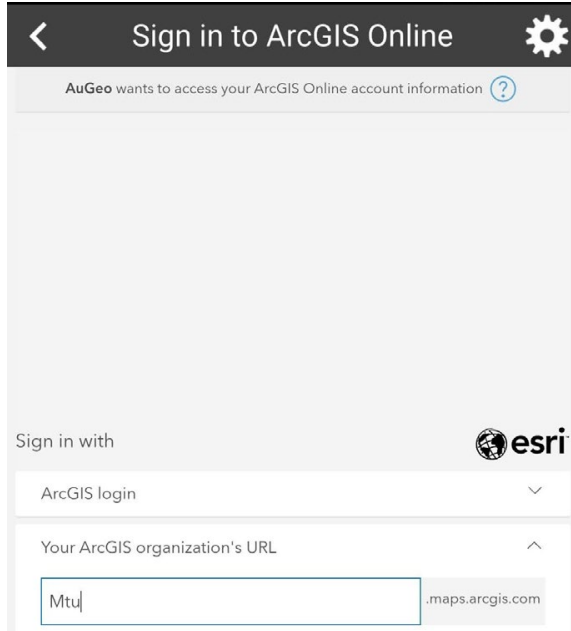

Figure 2: Accessing the MTU Single Sign On System application allowed for the usage of georeferenced CC-HSDI Sanborn Fire Insurance Plans as a "basemap" in the application. However, number of other features factored into this choice. AuGeo is readily available on both the Google Play and App Stores for free. It is published as and ESRI Labs application, meaning it is readily compatible with all ESRI formatted GIS data and therefore the data within

the CC-HSDI. AuGeo allows users to store spatial data locally, reducing the 
need for cellular data connections. Finally, it is also compatible with Michigan

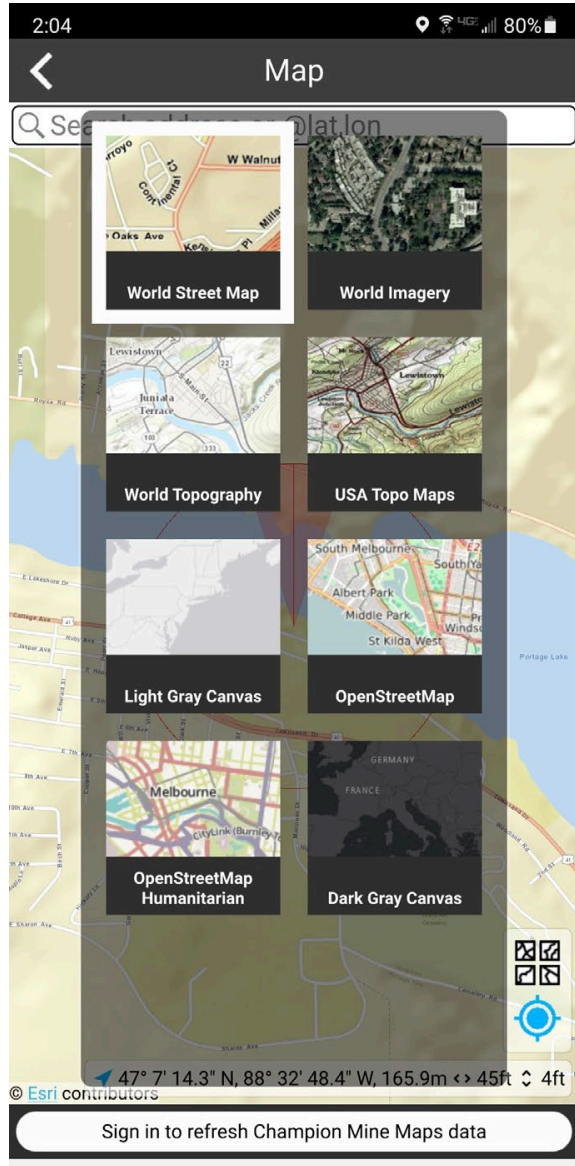

III

○

Technological University's Single Sign On (SSO)

system, allowing the study participants easy

access to all of the data they would need for the study.

AuGeo allows for the usage of "point

feature classes" to overlay a mobile device's

camera feed. A point feature class is a layer of

GIS data that has been mapped to a specific set

of geographic

coordinates,

and usually

contains a set

of attributes

Figure 3: AuGeo's Basemap Browser containing

relevant information for that dataset. There are

other forms of GIS data beyond points such as

polygons and lines. However, AuGeo is only

compatible with point data because it is the

simplest to display in an AR format. Points

within AuGeo display information as a "popup"

that can be selected by tapping the screen to

display descriptive text. Images contained within

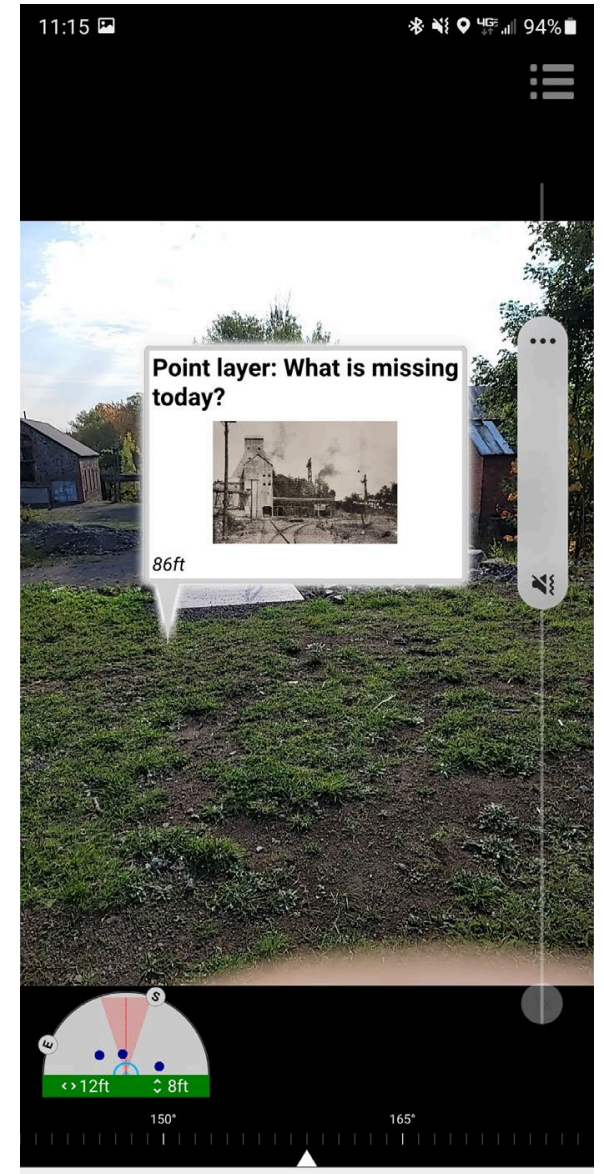

Figure 4: A Point Containing an Archival Photograph of the Champion Mine Shaft No. 4 


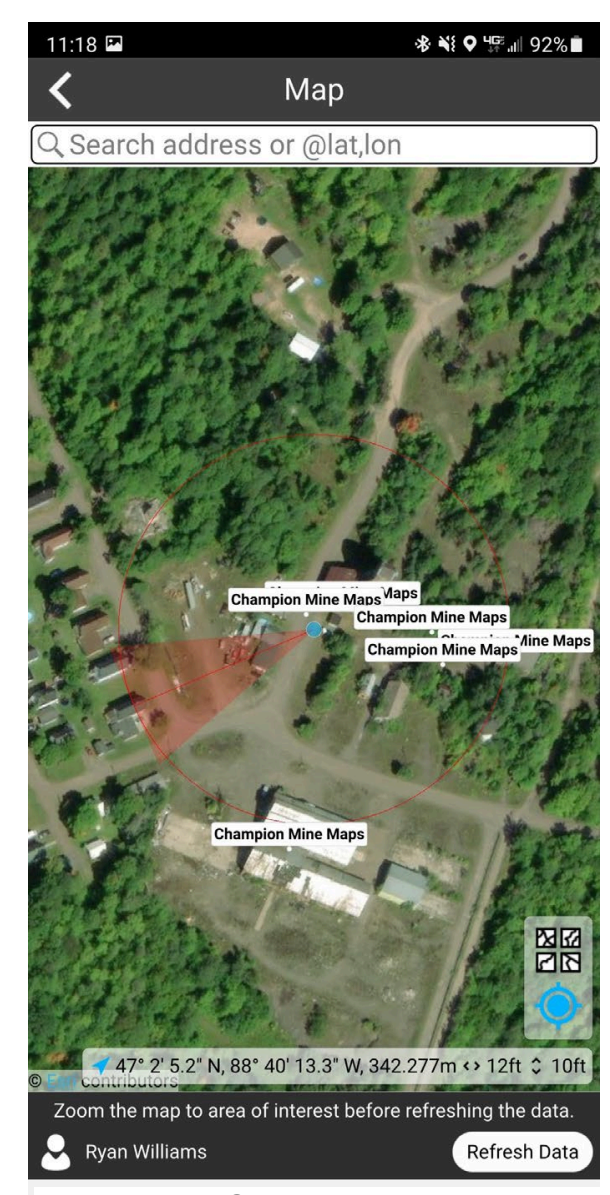

Figure 5: AuGeo's Navigational Map the popup will be displayed, but cannot be interacted with. By clicking the compass in the bottom left corner of the display, users can access a map displaying both the direction the user is facing, and all of the points of interest around them. By clicking those points on the map AuGeo will provide users an approximate direction and distance to reach that point. As implemented for this study there were three different layers of point data implemented in the application. The first layer contained various pieces of information found in the Michigan Technological University archives such as photographs, newspaper clippings, and mining company documents. The second layer contained entries found within the 1939 Houghton County Directory. Each entry contained the individual's name and profession in addition to their address, which allowed them to be mapped to a corresponding address on 1949 Sanborn Fire Insurance Plans. The final layer was designed to make up for the fact that the Sanborn Fire Insurance Plans could not be used as a basemap in AuGeo, closeup images of each structure on the map were placed at the corresponding location in the point layer and titled with any descriptive information written on the Fire Insurance Plan. 
Obviously a largely text description is not a good way to get an idea of an application's capabilities. To get a better idea of what this application is capable of, a video walkthrough can be found here: https://www.historicalgis.com/ To view the data itself readers can install AuGeo onto their mobile device unfortunately, the spatial data is only available to users with a Michigan Technological University login account via the SSO system login.

\subsection{Participant Selection}

The participants for this study were selected for both practical and mutually beneficial reasons. The 40 students in the third-year history course named "The Copper Country" (SS 3541) at Michigan Tech were selected as part of a collaborative effort with the course's instructor Dr. Laura Rouleau. This collaboration was mutually beneficial because this study also supported the course's goals in heritage education, specifically of landscape change of the Copper Country over time. These students were ideal candidates for a study like this because their technical literacy proved advantageous in streamlining the training process, and allowed them to use the Augmented Reality application on their own smartphones for both personal comfort and in optimizing set up time for the study, this approach maximized the time spent in the field using the app. Previous course activities also established background experience at industrial heritage sites with the class having previously visited the Quincy Smelter site in Hancock MI. However, the Quincy Smelter visit would prove to be 
substantially different from this experience as that was a guided tour with no involvement of augmented reality or GIS technologies. While their enrollment in a course on Copper Country history generally implies at least some interest in industrial heritage, previous course material provided additional context for the industrial landscape they were exploring with the app.

\subsection{Procedure}

The study was conducted in four phases. The first phase consisted of visiting the class to provide training for the usage of the AR application, and to allow the students to prepare the application and needed data on their own devices. The second phase was the distribution of the pre-study survey designed to evaluate student's experience with Augmented Reality applications and determine a baseline for their interest in the field of Industrial Heritage. Phase three consisted of the actual on-site study; allowing the students to freely explore the Champion Mine site using the AR application, while this author provided technical assistance when needed. Phase four was the distribution of the post-study survey; designed to identify key areas of interest either digital or physical and gather insights into participant's interpretations of the site, while documenting any changes in overall interest in industrial heritage. Both the pre and post surveys were administered via Canvas quizzes by the course instructor Dr. Rouleau. This method of distributing the surveys was chosen to ensure ease of access for the participants, because Canvas is used in all Michigan Technological University Courses. This ensured all of the students would know where to find the surveys and that the surveys would be in 
a place the participants would likely look on the day of the study. Additionally, both of these surveys are consistent with the qualitative design methodology used in similar studies (Cushing \& Cowan 2017, Kaplan \& Shiff 2017, Ellenberger 2017)

\subsubsection{Phase One}

During regularly scheduled class time on October $5^{\text {th }} .2021$ a brief training presentation was given to the participants, this consisted of a primer on the Keweenaw Time Traveler and its component datasets, some background information on the types of data that would be in the application to provide some surface level literacy with those sources; and a step by step tutorial showing how to download AuGeo, access/cache the relevant data to be used during the study, as well as walk the participants through some ease of use settings they would want to know about such as the ability to manually control the Compass on the application.

\subsubsection{Phase Two}

The pre-survey was administered via Canvas quiz the morning of the study (October $\left.7^{\text {th }}, 2021\right)$. The survey was due at the beginning of class and contained the following questions:

1. Do you have experience using AR applications? If yes, describe it.

2. What do you anticipate learning from this experience?

3. What is your interest in exploring historical mining landscapes 1-10 with 1 being not interested and 10 being very interested.

4. Do you feel like this will be a valuable experience? How? 


\subsubsection{Phase Three}

Participants were provided transportation to the study site via a bus leaving from campus immediately at 2:00pm. Some students chose to provide their own transportation to the site. The bus arrived at the stie at 2:15 pm a roughly 5-minute talk was given to explain the boundaries of the Champion Mine site, remind participants not to trespass

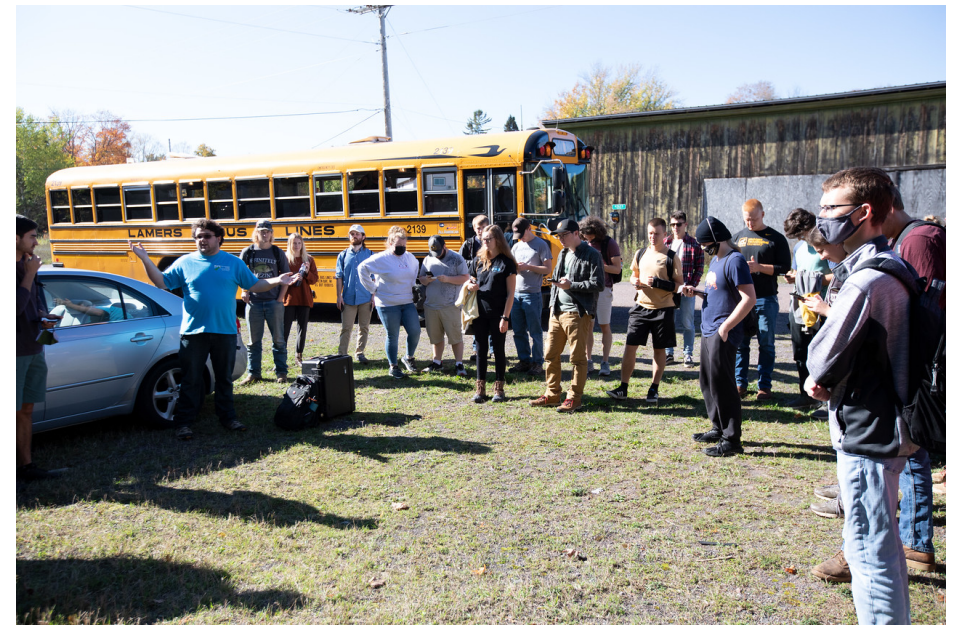

Figure 6: Briefing the Participants Before the Exploration on nearby residential properties, and to remind those taking the bus that it would be leaving by 3:00pm. Login information for the provided Wi-Fi hotspots was distributed and lastly it was reiterated to the participants that they were there to

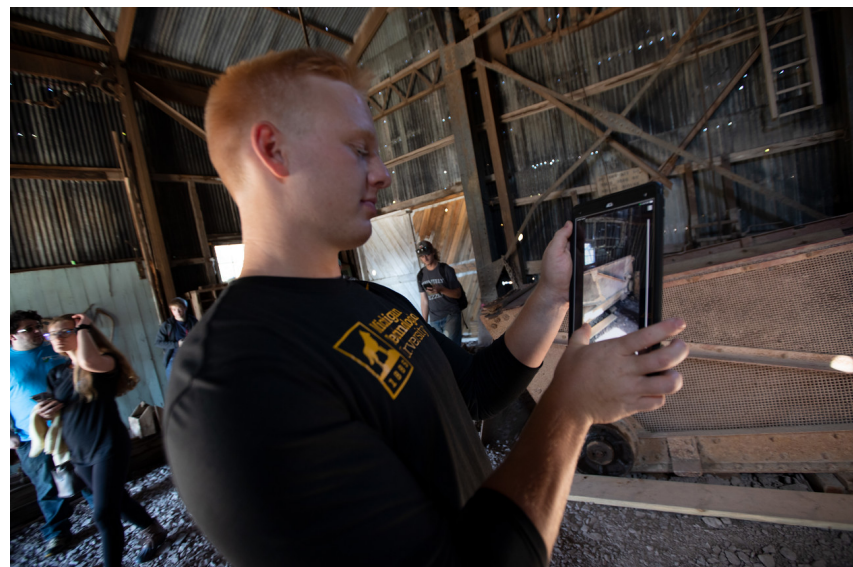

Figure 7: Participant Using the Application in the Shaft House use both the app and the remaining site features to create their own interpretations. At roughly $2: 20 \mathrm{pm}$ the participants dispersed around the site to begin exploring, they were given $\sim 40$ minutes to explore the area. During which time 4 students reported problems getting the data to load on their devices, which was quickly corrected by this author walking them through 
the login process to refresh the data. One participant reported difficulties with his device's compass, this author walked them through the activation of the manual compass control. One student had a

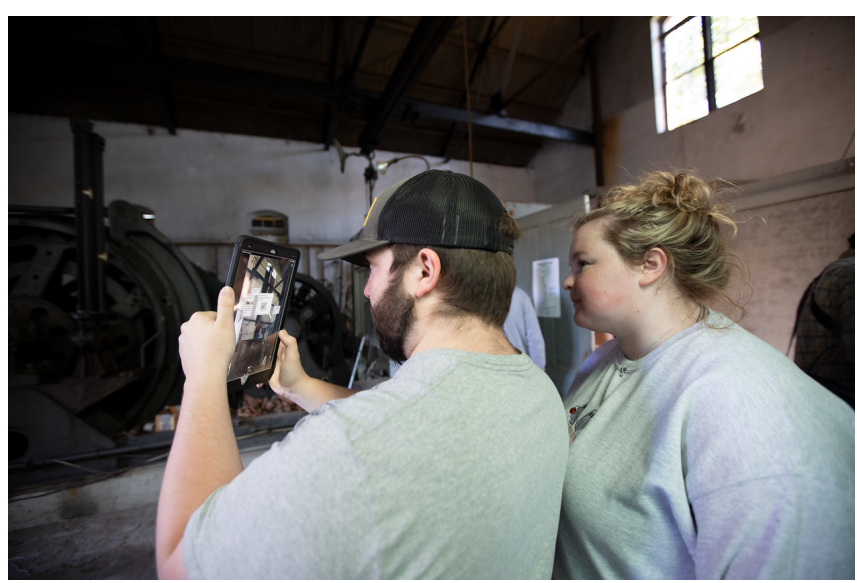

Figure 8: Participants Discussing Data From the Hoist House

failure of their device, it is unknown if it was due to damage or software incompatibility, which was rectified by providing them with an Ipad to use during the study. All of these issues were resolved within the first 10 minutes of the study. Over the course of the study participants covered roughly the entire grounds of the site, using the various datasets and the AR application to navigate. The sites that seemed to hold participant's interest the longest were

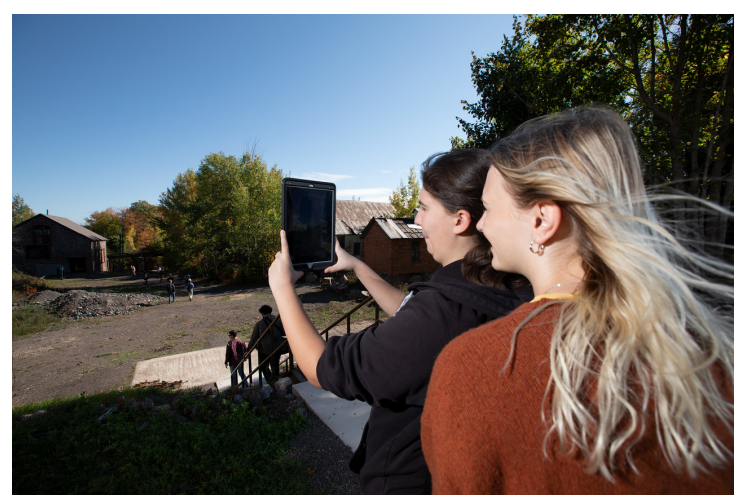

Figure 9: Participants Viewing the Landscape Through the App

the insides of the "Hoist" (Figure 4) and

"Shaft" (Figure 3) houses. This is likely due to the abundance of physical artifacts present in both spaces, allowing for a myriad of both digital and physical interpretations to be made. Ultimately it seemed like there was not enough time for participants to thoroughly explore all of the material available within the time frame, particularly when it came to the residences adjacent to the 
Champion Mine site. This may be due to a reluctance to disturb current residents, or to stray too far from the group and transportation.

\subsubsection{Phase Four}

The post-survey was administered via Canvas quiz and was made available immediately after the class period until midnight to ensure the experience was fresh in the participant's minds when filling out the survey. The post-survey contained the following questions:

1. Did this experience match what you anticipated learning? How? If not, why?

2. Did anything at the site (physical or digital) stand out to you? What and why?

3. Describe how the AR application impacted how you explored and interpreted the landscape we visited today.

4. Describe how the landscape has changed over time.

5. What questions about this site do you still have? How might you answer those questions?

6. After using the AR application rate your interest in exploring historical mining landscapes $1-10$ with 1 being not interested and 10 being very interested.

7. Would you use technology like this again if it were available? 


\subsection{Concerns}

The primary concern when organizing this study was the availability of a study site. In the initial planning phase of this study a section of downtown Calumet along Fifth Street was selected, this was due to the ready availability of data to be used via the Keweenaw Time Traveler and Copper Country Historical Data Infrastructure (CCHSDI). However, as the study date drew nearer there was concern that the participants would be unable to get back from the proposed study site in Calumet within the available time frame without significantly sacrificing time exploring the site. This concern was due to a delay in construction on the Portage Lake Lift Bridge. This led to the Champion mine site being selected as the alternate site. However, beyond just travel time, the Champion Mine supported not just the study through its status as an industrial heritage site, but through the fulfilment of the course requirements of landscape change that needed to be met in collaboration with the study. It was later learned that the utilization of this site also further supported the larger goals of the IHA program by cultivating community relationships by making connections with the caretakers of the site. One of which, Scott See being, a graduate of the Industrial Archaeology program. It should also be noted that the datasets described earlier in this section needed to be constructed to compensate for this change in venue, rather than just using the readily available data within the Keweenaw Time Traveler.

There is also a concern that the fact that the surveys were administered by the course instructor may have influenced responses. There may have been 
an influence to provide more positive responses due to the lack on anonymity required to match up the different responses. However, it was determined that ease of access was more important than anonymity. Paper surveys administered on the way to and from the study site were considered, but rejected because some students preferred to provide their own transportation to the site, and ensuring that was an option was important due to the ongoing Covid-19 pandemic making travel by bus a concern for some students. The surveys could not have been administered at the Champion Mine because that would have taken up too much of the class period that would otherwise have been used to explore the site.

Other minor concerns were wireless signal and technical issues. Wireless signal was addressed by visiting the site beforehand to test device connections, and providing wireless access points to ensure network access was available to all participants. To address potential technical issues this author was available to provide technical support, and Ipads with the correct software and data were prepared in case for some reason participants did not have a device of their own or there were any other reasons they could not use their own device (such as software incompatibility, dead batteries, or hardware failures).

\subsection{Ethics}

There were a few areas of ethical concerns that were considered; the first two of which were the use of the application itself, and that of the potential physical 
hazards to participants that naturally come with the Champion Mine site being a partially remediated industrial site. The application makes users aware that it will be using location data and the rear facing camera (permissions agreements the participants are already familiar with), and a verbal reminder was given to participants at the beginning of the study not to trespass on private property beyond the outlined heritage site and to be mindful of potentially dangerous items still located at the site. The main concern that could potentially affect the results of this study is the potential for students to have felt pressured to respond positively in the survey because it was administered by Dr. Rouleau, their course instructor. For IRB approval it was determined that this project was covered under pre-existing IRB approval for the Keweenaw Time Traveler Project. 


\section{Results}

Out of 40 students in The Copper Country course 31 students responded to the post-survey, with one of those respondents having not responded to the presurvey; a response rate of roughly $75 \%$. 18 of the respondents reported having no previous experience with Augmented Reality, 12 reported some experience, largely through AR mobile games such as Pokémon Go. This demonstrates that this sample had little more than passing familiarity with AR experiences before this study, suggesting that their responses were likely not heavily influenced through previous experiences.

\subsection{Change in interest}

Before the study participants reported an average interest in Industrial Heritage of 8.34 on a scale of 1 to 10 , supporting the idea that these participants had an initial interest higher than most people. However, without a larger control group this is unverifiable. After the study their reports showed an average interest of 7.85 out of 10 with 5 respondents showing

Table 1: Description of Participant Change in Interest

\begin{tabular}{|l|l|}
\hline $\begin{array}{l}\text { Number of students with } \\
\text { increased interest }\end{array}$ & 5 \\
\hline Average increase & 1.6 \\
\hline $\begin{array}{l}\text { Number of students with } \\
\text { decreased interest }\end{array}$ & 9 \\
\hline Average Decrease & -2.52 \\
\hline Overall average change & -0.49 \\
\hline Standard Deviation & 1.51 \\
\hline
\end{tabular}
slightly increased interest and 9 respondents showing reduced interest. Some of this average decrease can be accounted for through two outliers showing 
decreased interest, with their reported decreases in interest of -4 and -6 falling more than 2 standard deviations outside the norm for respondents. However, these outliers do not account for all of the negative change. Some of this may be due to fatigue from respondents needing to fill out both surveys on the same day of the study, administering the pre-survey during the original consultation with the class may alleviate the possibility of this fatigue in future studies.

\subsection{Respondent Experiences}

Responses were classified as "positive" Table 2: Participant Experiences and Expectations

"negative" or "mixed" based on explicit statements of those experiences as well as a more arbitrary determination of tone. Some responses are included to give an idea of what types of responses were classified in each category. 19

respondents described experiences that

\begin{tabular}{|l|l|}
\hline Positive Experiences & 19 \\
\hline Negative Experiences & 6 \\
\hline Mixed Experiences & 6 \\
\hline Met Expectations & 23 \\
\hline Did Not Meet Expectations & 8 \\
\hline
\end{tabular}
were characterized as "positive". Some

"I was expecting the app to give a sort of self-guided tour and it did not disappoint. It pointed out key features of the landscape for us to explore. It was easier to get a visualization of all of the parts of the mine as they might have worked in their heyday."

"Although present day the site was run down and abandoned, using the AR app really made the site come alive and make it interesting and informative!" common sentiments expressed

included 5 responses noting

that respondents liked the

"freedom of exploration" the app

Figure 10: Examples of Positive Experiences allowed over guided tours, 7 
responses

highlighted how

they felt the app

showed them

information they
"Overall, the experience of using AR synced with my anticipation of learning given that the tool was able to help me understand the buildings that I was in. I was able to see and learn about the buildings while exploring the area unguided. Overall, however, the AR tool was less conducive to my learning experience than a tour guide would have been. In general, I think I would have learned significantly more about the area and the buildings if we had toured the area in a guided fashion. In many ways, the AR application felt distracting to the experience. I often avoided using it once I was in an area to ensure that I could physically enjoy the space that I was in."

would not have otherwise

Figure 11: An Example of a Mixed Experience

been

able to find at the site. 6 responses were characterized as "mixed" experiences,

many of these responses expressed a desire for the application to provide the participants with more detailed or specific information about

"I anticipated the AR experience to feel more integrated, maybe it is just my personality but I was more interested in seeing what was directly in front of me rather than virtually."

"I used it for about 5 minutes then put my phone away and instead looked around and wandered without it. It did not impact how I interpreted the landscape much, if at all."

Figure 12: Examples of Negative Experiences buildings/events/people. 6 responses were categorized as "negative" experiences, some of them also expressed a desire for more specific information to be displayed within the app, 3 mentioned technical issues that went unreported during the study and 4 expressing a more personal dislike of the application or a preference for unaided exploration. 


\subsection{Other Findings}

24 respondents reported that

the experience met their

expectations and 7 reported that

it did not. These unmet

expectations heavily correlated

with "mixed" and "negative"

responses. 9 responses
"The AR application impacted how I explored in that it led me to places that did not stand out, but stood out on the app itself."

"It provided a rough direction of where points of interest were."

"The AR application primarily acted as a tour guide for me in wondering around the site."

"I had some difficulties getting it to work which might have been the compass on my phone. When it did work, the popups helped to guide me to new places to explore or read more about."

Figure 14: Examples of Responses Stating the App Aided in Navigation

specifically mentioned some way in which

the app helped them to navigate around the site. 18 respondents reporting they would use a similar application again, 12 respondents reporting that they might use one, and 1 reporting that they would not. In keeping with the goals, the of the "Copper Country" course when asked to elaborate on how they were interpreting the site and or the post-industrial landscape all but one respondent

"I would like to know more details regarding production rate, depth of the mine, number of employees etc."

"I am still curious as to some of the purposes of the buildings on the property. I was unable to perfectly visualize the process of copper extraction at this site."

"How deep is the mine shaft? How much copper was taken out of this mine? How many people worked here?"

Figure 13: Examples of Inquiries was able to elaborate on some interpretation they were able to make about the make. Also relating to the course goals, the final question prompted respondents to elaborate on questions they had about the site, and how/where 
they might go to find that information, only 3 respondents did not elaborate on further inquiries they wanted to make about the site. These inquiries are also important moving forward as they will help give direction in how to improve the application and address the shortcomings noted in the mixed and negative responses. It should be noted that these responses likely include error of their own due to factors such as the way they were administered discussed earlier and that these surveys were not professionally designed, meaning the questions may not have yielded answers perfectly suited to answer the original research question. However, the information gathered in this process still provides a valuable opportunity to discuss how this application performed and how the future implementation of augmented reality in industrial heritage education and interpretation can be improved. 


\section{Discussion}

This study demonstrated that there is potential for AR to serve the fields of industrial heritage and education as a navigational tool for heritage sites, particularly ones that occupy larger landscapes with potentially significant missing structures. With nearly $1 / 3^{\text {rd }}$ of respondents specifically mentioning how the application helped them navigate the site, this demonstrates a potential avenue for further study to "dial in" the types of information and modes of presentation through AR that would most effectively allow users to navigate such heritage site. This result is encouraging for this line of inquiry as it was unexpected and did not stem from any specific questioning, and no responses demonstrated that the application made it more difficult to navigate the site.

While the overall tone of responses demonstrated a majority positive experience with the AR application with roughly $60 \%$ responding with entirely positive feedback, only 18 out of 31 respondents replied that they would use a similar application if available, leaving the vast majority of the rest of the responses (12 out of the 13 remaining) unconvinced with "maybe" answers. This demonstrates that there is still a question of whether or not this AR tool really is valuable in this use case, especially with the responses indicating an overall decrease in heritage interest (even when accounting for outliers). For the responses coded as "Negative" (6 response) and "Mixed" (6 responses), there is a clear correlation to unmet expectations (8 responses), as well as technical 
issues (3 responses) and/or some other general dislike of the application (4 responses). Technical issues will always be a problem when evaluating any sort of digital resource and it is inevitable that some users may just not like using technology. However, there is the potential to try and address those unmet expectations.

Feedback describing a perception of 'shallowness' is largely consistent with findings of other similar studies such as the ones undertaken by Cushing and Cowan (2017) and Kaplan and Schiff (2017). In the context of this study, it is unclear if these shortcomings are due to unrealistic expectations set by participants or if the original consultation with the class set expectations that would never have been able to be met by the testing application. However, with some improvements to the application allowing for more detailed information about specific data such as; company records and personal experiences, many of the criticisms and disappointments experienced by participants could be assuaged. One way in which those improvements could be made is by focusing on specific historical narratives in a similar fashion to other AR heritage projects like the "Walk 1916" and "Mapping Ararat" projects discussed in the literature review (Cushing \& Cowan 2017, Kaplan \& Shiff 2017). Though, this solution comes with the caveat that those studies also experienced similar issues with a perceived "shallowness", perhaps different results will be found by utilizing the different datasets within the CC-HSDI? Another way in which this could be explored is by performing a similar general study at another heritage site that has 
more robust historical spatial data available than at the Champion Mine, sites such as the Quincy Mine and Smelter, Main Street Calumet, Michigan Technological University's campus, and many other sites located within in the Copper Country. These perceived shortfalls could also be addressed at the design stage of the application itself, by allowing a greater degree of freedom for users when interacting with the application, for example allowing users to zoom into images to allow for more meaningful incorporation of datasets such as company records or newsprint. By implementing one or more of these potential solutions, further inquiry should likely find a more positive reaction from participants, suggesting the potential for tools such as this to bring positive industrial heritage and education experiences to users. Given these findings, it seems to be too early to truly consider how implementing AR applications such as this might impact heritage organizations. However, further including heritage organizations in the development of these applications may provide valuable information in how to best tailor these applications to fit their needs. Were this author to undertake a similar study, it would ideally be done at one of those more data-rich sites listed previously, and the design of the application would incorporate the ability for users to more freely interact with the images displayed by the application.

Another way in which an application like this might be utilized is to more specifically study the idea of Data Democratization. A concept introduced to this author by Cushing \& Cowan's (2017) work, Data Democratization is the idea that 
data which is traditionally used in university settings for research purposes should be made readily available to users outside of that setting to allow them to create their own interpretations outside of the perspective of researcher's monopolization of those resources. This meshes with the public facing goals of projects like the Keweenaw Time Traveler, especially with the elements of public participation that project has already incorporated (Lafreniere et al 2019). Bringing the full breadth of the CC-HSDI into an Augmented Reality interface not only provides another way for users to interact with that data aside from KeTT, but provides users an opportunity to interact with that data within its original spatial context in ways they could not before. Using AR and HSDls as way to support Data Democratization represents an opportunity for users to continue creating their own new interpretations. This idea is supported by the findings of this study as all of the respondents were able to come up with some sort of interpretation of their own, and all but one respondent was able to formulate an inquiry about something else they wanted to learn about the site.

To reconsider the original research question:

How can the integration of Augmented Reality technologies with Historical Spatial Data Infrastructures support industrial heritage interpretation and education?

Ultimately this study showed that there is the potential for AR to be used to support industrial heritage interpretation and education by augmenting 
interpretive materials and providing users with the freedom to navigate and explore sites using their own devices. However, it also demonstrated that the design of these applications is important and needs interactivity and depth to meet the potential needs for users. These results serve as a call for future studies to incorporate these findings into applications that will more effectively serve the needs of heritage organizations moving forward. 


\section{Reference List}

- Arnold, John David McEwen, and Don Lafreniere. "Creating a longitudinal, datadriven 3D model of change over time in a postindustrial landscape using GIS and CityEngine." Journal of Cultural Heritage Management and Sustainable Development (2018).

- Arnold, J., and Lafreniere, D. 2017. The Persistence of Time: Vernacular Preservation of the Postindustrial Landscape. Change Over Time: An International Journal of Conservation and the Built Environment, Vol. 7, no. 1: $114-133$

- Barceló, Joan A, Michele Calvano, Ivan Campana, Raquel Piqué, Antoni Palomo, and Josep O Bultó. "Rebuilding the Past: 3D Reconstruction and BIM Analysis of a Neolithic House at La Draga (Girona, Spain)." In Digital Cultural Heritage, 157168. Cham: Springer International Publishing, 2019.

- Besser, Howard. "Image databases: The first decade, the present, and the future." Digital Image Access \& Retrieval [papers presented at the 1996 Clinic on Library Applications of Data Processing, March 24-26, 1996 Urbana-Champaign] (1997).

- Birkfellner, W, M Figl, K Huber, F Watzinger, F Wanschitz, J Hummel, R Hanel, et al. "A Head-Mounted Operating Binocular for Augmented Reality Visualization in Medicine - Design and Initial Evaluation." IEEE transactions on medical imaging 21, no. 8 (2002): 991-997.

- Casimiro, Giovanna. "Augmented Heritage: Digital Tools for Historical Experience." In Proceedings of the 9th International Conference on Digital and Interactive Arts, 1-5. ACM, 2019.

- Compeau, Timothy J, and Kevin Kee. Seeing the Past with Computers: Experiments with Augmented Reality and Computer Vision for History. Ann Arbor: University of Michigan Press, 2019.

- Cushing, Cowan. "Walk1916: Exploring Non-Research User Access to and Use of Digital Surrogates via a Mobile Walking Tour App." Journal of documentation 73, no. 5 (September 11, 2017): 917-933.

- Davies, Jamie. "On-site Digital Heritage Interpretation: Current uses and future possibilities at World Heritage Sites." Durham: Durham University (2014).

- DeBats, Donald A., and lan N. Gregory. 2011. "Introduction to Historical GIS and the Study of Urban History." Social Science History 35 (4). Cambridge University Press: 455-63. doi:10.1017/S0145553200011639.

- Deggim, S., T. P. Kersten, F. Tschirschwitz, and N. Hinrichsen. "Segeberg 1600reconstructing a historic town for virtual reality visualisation as an immersive experience." The International Archives of Photogrammetry, Remote Sensing and Spatial Information Sciences 42 (2017): 87.

- Delić, Alen, Mirna Domančić, Petra Vujević, Neven Drljević, and Ivica Botički. "AuGeo: A geolocation-based augmented reality application for vocational geodesy education." In Proceedings ELMAR-2014, pp. 1-4. IEEE, 2014.

- De Moor, Martina, and Torsten Wiedemann. "Reconstructing territorial units and hierarchies: A Belgian example." History and Computing 13, no. 1 (2001): 71-97.

- Driese, Kenneth L., Reiners, William A., Merrill, Evelyn H., and Gerow, Kenneth G. "A Digital Land Cover Map of Wyoming, USA: A Tool for Vegetation Analysis." Journal of vegetation science 8, no. 1 (1997): 133-146. 
- Dunae, Patrick A., Donald J. Lafreniere, Jason A. Gilliland, and John S. Lutz. "Dwelling places and social spaces: revealing the environments of urban workers in Victoria using historical GIS." Labour/Le Travail (2013): 37-73.

- Eckert, Martin, Julia S Volmerg, and Christoph M Friedrich. "Augmented Reality in Medicine: Systematic and Bibliographic Review." JMIR mHealth and uHealth 7, no. 4 (2019): e10967-e10967.

- Ellenberger, Kate. "Virtual and augmented reality in public archaeology teaching." Advances in Archaeological Practice 5, no. 3 (2017): 305-309.

- Gilliland, Jason A., Sherry H. Olson, and Danielle Gauvreau. "Did segregation increase as the city expanded? The case of Montreal, 1881-1901." Social Science History (2011): 465-503.

- González-Tennant, Edward. "Collaborative Archaeology, Social Justice, and Digital Heritage in Rosewood." In The Rosewood Massacre. University Press of Florida, 2018.

- GREGORY, Ian N, Chris BENNETT, Vicki L GILBAM, and Humphrey R SOUTHALL. "The Great Britain Historical GIS Project: From Maps to Changing Human Geography." Cartographic journal 39, no. 1 (2002): 37-49.

- Gregory, Ian N., Karen K. Kemp, and Ruth Mostern. "Geographical information and historical research: Current progress and future directions." History and Computing 13, no. 1 (2001): 7-23.

- Heide, Anna Maria, Pascal Fallavollita, Lejing Wang, Philipp Sandner, Nassir Navab, Simon Weidert, and Ekkehard Euler. "Camera-augmented Mobile C-arm (CamC): A Feasibility Study of Augmented Reality Imaging in the Operating Room." The international journal of medical robotics + computer assisted surgery 14, no. 2 (2018): e1885-n/a.

- Hildebrandt, R., Lafreniere, D., and Xie, Y. (in review) Empowering Youth to Be a Voice in Neighborhood Change Through Geospatial Technologies. Children's Geographies (2021)

- Hodgson, Eric, Eric Bachmann, and David Waller. "Redirected Walking to Explore Virtual Environments: Assessing the Potential for Spatial Interference." ACM transactions on applied perception 8, no. 4 (2011): 1-22.

- Holdsworth, Deryck W. "Historical Geography: New Ways of Imaging and Seeing the Past." Progress in human geography 27, no. 4 (2003): 486-493.

- Holdsworth, Deryck W. "Historical Geography: The Ancients and the Moderns Generational Vitality." Progress in human geography 26, no. 5 (2002): 671-678.

- Jaillot, Vincent, Manon Istasse, Sylvie Servigne, Gilles Gesquière, Michel Rautenberg, and Isabelle Lefort. "Describing, Comparing and Analysing Digital Urban Heritage Tools: A Methodology Designed with a Multidisciplinary Approach." Digital Applications in Archaeology and Cultural Heritage 17 (2020): e00135-.

- Kaplan, Shiff. "Mapping Ararat: An Augmented Reality Walking Tour for an Imaginary Jewish Homeland." Anthrovision, no. 4.2 (July 9, 2017).

- Knowles, Anne Kelly. "Emerging trends in historical GIS." Historical Geography 33 (2005): 7-13.

- Knowles, Anne Kelly, Justus Hillebrand, Paul B Jaskot, and Anika Walke. "Integrative, Interdisciplinary Database Design for the Spatial Humanities: The Case of the Holocaust Ghettos Project." International journal of humanities and arts computing 14, no. 1-2 (2020): 64-80.

- Kennedy, S. Wright, Andrew J Curtis, and Jacqueline W Curtis. "Historic Disease Data as Epidemiological Resource: Searching for the Origin and Local Basic 
Reproduction Number of the 1878 Yellow Fever Epidemic in Memphis, Tennessee." Annals of the Association of American Geographers 105, no. 5 (2015): 1-16.

- Kremers, Horst. Digital Cultural Heritage. 1st ed. 2020. Cham: Springer International Publishing, 2020.

- Kreutel, Jörn. "Augmenting Network Analysis with Linked Data for Humanities Research.” In Digital Cultural Heritage, 1-14. Cham: Springer International Publishing, 2019.

- Lafreniere, D., and Gilliland, J. 2015. “All the World's a Stage”: A GIS Framework for Recreating Personal Time-Space from Qualitative and Quantitative Sources. Transactions in GIS, Vol. 19, no. 2: 225-246.

- Lafreniere, Don, Luke Weidner, Daniel Trepal, Sarah Fayen Scarlett, John Arnold, Robert Pastel, and Ryan Williams. "Public Participatory Historical GIS." Historical Methods 52, no. 3 (July 2019): 132-49. doi:10.1080/01615440.2019.1567418.

- $\quad$ Lafreniere, D., Stone, T., Hildebrandt, R., Sadler, R., Madison, M., Trepal, D., Spikberg, G., and Juip, J. 2021. Schools as Vectors of Infectious Disease Transmission during the 1918 Influenza Pandemic. Cartographica: The International Journal for Geographic Information and Geovisualization. DOI: 10.3138/cart-2020-0025

- LeMire, Graves. "Libr-AR-y Tours: Increasing Engagement and Scalability of Library Tours Using Augmented Reality." College \& undergraduate libraries 25, no. 3 (July 3, 2018): 261-279.

- $\quad$ Li, Hua, Xin Zhang, Guangwei Shi, Hemeng Qu, Yanxiong Wu, and Jianping Zhang. "Review and Analysis of Avionic Helmet-Mounted Displays." Optical engineering 52, no. 11 (2013): 110901-110901.

- LOCK, GARY. "Representations of Space and Place in the Humanities." In The Spatial Humanities, 89-. Indiana University Press, 2010.

- Lock, Gary, and John Pouncett. "Spatial thinking in archaeology: Is GIS the answer?." Journal of Archaeological Science 84 (2017): 129-135.

- Marini, D, M Rossi, L Moltedo, and O Salvetti. "Virtual Reality and Web Tools to Convey the Visual Information of Ancient Monuments." Computer networks and ISDN systems 29, no. 14 (1997): 1655-1660.

- Mezzino, D., Barazzetti, L., Santana Quintero, M., and El-Habashi, A.. "DIGITAL TOOLS FOR DOCUMENTING AND CONSERVING BAHRAIN'S BUILT HERITAGE FOR POSTERITY." International archives of the photogrammetry, remote sensing and spatial information sciences. XLII-2-W5 (2017): 513-519.

- Nausheen, Fauzia, and Renu Bhupathy. "Disrupting Clinical Education: Point-ofcare Ultrasound Merged with HoloLens Augmented Reality During Early Medical Training." The clinical teacher 17, no. 2 (2020): 146-147.

- Novak, Mathew J., and Jason A. Gilliland. 2011. "Trading Places: A Historical Geography of Retailing in London, Canada." Social Science History 35 (4). Cambridge University Press: 543-70. doi:10.1017/S0145553200011664.

- Olson, Sherry H., and Patricia A. Thornton. Peopling the North American City Montreal, 1840-1900 Montreal ;: McGill-Queen's University Press, 2011.

- Parrinello, Sandro, and Federico Cioli. "Establishment of a Complex Database for the Study of Cultural Heritage Through the Reading and Analysis of the Traditional Architecture of Upper Kama." In Digital Cultural Heritage, 51-61. Cham: Springer International Publishing, 2019 
- Quintero, Mario Santana, Bill Blake, and Rand Eppich. "Conservation of Architectural Heritage: The Role of Digital Documentation Tools: The Need for Appropriate Teaching Material." International journal of architectural computing 5 , no. 2 (2007): 239-253.

- Ramos, Francisco, Sergio Trilles, Joaquín Torres-Sospedra, and Francisco J. Perales. "New Trends in Using Augmented Reality Apps for Smart City Contexts." ISPRS International Journal of Geo-Information 7, no. 12 (2018).

- Ridge, Mia, Don Lafreniere, and Scott Nesbit. "Creating Deep Maps and Spatial Narratives through Design." International journal of humanities and arts computing 7, no. 1-2 (2013): 176-189.

- Ruggles, Steven, Evan Roberts, Sula Sarkar, and Matthew Sobek. "The North Atlantic Population Project: Progress and Prospects." Historical methods 44, no. 1 (2011): 1-6.

- Sadler, Richard Casey, and Don J. Lafreniere. "Racist housing practices as a precursor to uneven neighborhood change in a post-industrial city." Housing studies 32, no. 2 (2017): 186-208.

- Sadler, Richard C., Jason A. Gilliland, and Godwin Arku. "An application of the edge effect in measuring accessibility to multiple food retailer types in Southwestern Ontario, Canada." International journal of health geographics 10 , no. 1 (2011): 1-15.

- Santana-Quintero, Mario, and Alonzo C Addison. "Digital Tools for Heritage Information Management and Protection: The Need of Training." In Virtual Systems and Multimedia, 35-46. Berlin, Heidelberg: Springer Berlin Heidelberg, n.d.

- Scarlett, Sarah Fayen, Don Lafreniere, Daniel J. Trepal, John DM Arnold, and Robert Pastel. "Engaging Community and Spatial Humanities for Postindustrial Heritage: The Keweenaw Time Traveler." American Quarterly 70, no. 3 (2018): 619-623.

- Scarlett, Sarah Fayen, Don Lafreniere, Daniel J. Trepal, John DM Arnold, and Yichun Xie. "Out of the Classroom and into History: Mobile Historical GIS and Community-Engaged Teaching." History Teacher 53, no. 1 (2019): 11-35.

- Scarlett, S., Lafreniere, D., Trepal, D., Arnold, J., and Xie, Y. 2019. Out of the Classroom and Into History: Mobile Historical GIS and Community-Engaged Teaching. The History Teacher, Vol. 53, no. 1: 11-35.

- Soni, Smit, and Anouk Lamontagne. "Characterization of Speed Adaptation While Walking on an Omnidirectional Treadmill." Journal of neuroengineering and rehabilitation 17, no. 1 (2020): 153-153.

- Southall, Humphrey, and Don Lafreniere. "Working with the public in historical data creation." (2019): 129-131.

- STEPHENSON, CHRISTIE. "Recent Developments in Cultural Heritage Image Databases: Directions for User-Centered Design." Library trends 48, no. 2 (1999): 410.

- Sutherland, Ivan E. "A head-mounted three dimensional display." In Proceedings of the December 9-11, 1968, fall joint computer conference, part I, pp. 757-764. 1968.

- Trepal, D., and Lafreniere, D. 2019. Understanding Cumulative Hazards in a Rustbelt City: Integrating GIS, Archaeology, and Spatial History. Urban Science, Vol. 3, no. 3: article 83. DOI: 10.3390/urbansci3030083

- Trepal, D., Lafreniere, D., and Gilliland, J. 2020. Historical Spatial-Data Infrastructures for Archaeology: Towards a Spatiotemporal Big-Data Approach to 
Studying the Postindustrial City. Historical Archaeology, Vol. 54, no. 2: 424452. DOI: $10.1007 / \mathrm{s} 41636-020-00245-5$

- Trepal, Dan, Lafreniere Don, and Stone Timothy. "Mapping Historical Archaeology and Industrial Heritage: The Historical Spatial Data Infrastructure." Journal of Computer Applications in Archaeology 4, no. 1 (2021): 202-213.

- Trepal, D., Scarlett, S., and Lafreniere, D. 2019. Heritage making through community archaeology and the spatial humanities. Journal of Community Archaeology \& Heritage, Vol. 6, no. 4: 238-256.

- Von Jan, U, C Noll, M Behrends, and U.-V Albrecht. "MARble - Augmented Reality in Medical Education." Biomedizinische Technik 57 (2012): 67-70.

- Withers, Charles W. J.. "Place and the 'Spatial Turn' in Geography and in History." Journal of the history of ideas 70, no. 4 (2009): 637-658.

- Wyeld, Theodor G., Sarah. Kenderdine, and Michael. Docherty. Virtual Systems and Multimedia 13th International Conference, VSMM 2007, Brisbane, Australia, September 23-26, 2007, Revised Selected Papers 1st ed. 2008. Berlin, Heidelberg: Springer Berlin Heidelberg, 2008.

- "Seminar on Convergence in the Digital Age: Challenges for Libraries, Museums and Archives." Asian libraries: the library \& information services journal 7, no. 6 (1998). 
A Appendix

Table A.1 Pre-Survey Questions and Responses

Attached

Table A.2 Post-Survey Questions and Responses

Attached 


\section{B Photo Copyright documentation}

Figure 6: Monte, Matthew, photographer. "A52A6876" Photograph. Houghton, Michigan. Michigan Tech Social Sciences. From mattmonte.smugmug.com. https://photos.smugmug.com/MTU/MTUSocialSciences/PainesdaleMineAugReali ty/n-cRSgdN/i-j2HsLvL/0/42cbb5e2/X2/i-j2HsLvL-X2.jpg (accessed November 9, 2021)

Figure 7: Monte, Matthew, photographer. "A52A6899" Photograph. Houghton, Michigan. Michigan Tech Social Sciences. From mattmonte.smugmug.com. https://photos.smugmug.com/MTU/MTUSocialSciences/PainesdaleMineAugReali ty/n-cRSgdN/i-NKr2HSS/0/138b3faa/X2/i-NKr2HSS-X2.jpg (accessed November 9, 2021)

Figure 8: Monte, Matthew, photographer. "A52A6966" Photograph. Houghton, Michigan. Michigan Tech Social Sciences. From mattmonte.smugmug.com. https://photos.smugmug.com/MTU/MTUSocialSciences/PainesdaleMineAugReali ty/n-cRSgdN/i-KJ4WNg2/0/25cdb5ad/X2/i-KJ4WNg2-X2.jpg (accessed November 9, 2021)

Figure 9: Monte, Matthew, photographer. "A52A6948" Photograph. Houghton, Michigan. Michigan Tech Social Sciences. From mattmonte.smugmug.com. https://photos.smugmug.com/MTU/MTUSocialSciences/PainesdaleMineAugReali ty/n-cRSgdN/i-m7bgXRq/0/e6d3d67a/X2/i-m7bgXRq-X2.jpg (accessed November 9, 2021) 


\begin{tabular}{|c|c|c|c|}
\hline $\begin{array}{l}\text { Do you have } \\
\text { experience } \\
\text { using AR } \\
\text { applications? }\end{array}$ & If yes briefly describe that experience: & What do you anticipate learning from this experience? & $\begin{array}{l}\text { Please rate your } \\
\text { interest in exploring } \\
\text { historical mining } \\
\text { landscapes }\end{array}$ \\
\hline No & & $\begin{array}{l}\text { An interactive experience to learn more about the } \\
\text { history and be able to relate to its location/environment } \\
\text { as seen today. }\end{array}$ & 6 \\
\hline No & $\begin{array}{l}\text { I have never used any AR applications } \\
\text { before. }\end{array}$ & $\begin{array}{l}\text { I anticipate to learn both how to use AR technology and } \\
\text { some cool history of the site in Painesdale we are } \\
\text { visiting. }\end{array}$ & 10 \\
\hline No & & $\begin{array}{l}\text { I anticipate learning how to use the AR kewennaw } \\
\text { history map, and some history about the copper } \\
\text { country. }\end{array}$ & 9 \\
\hline No & & The use of technology and what it can do for history. & 10 \\
\hline No & & $\begin{array}{l}\text { Learning more about painesdale mine and the } \\
\text { applicability of augmented reality to tourism/ museums. }\end{array}$ & 8 \\
\hline Yes & Kinda janky, but cool none the less. & Lots of niche and interesting history stuff. & 6 \\
\hline Yes & $\begin{array}{l}\text { I have only played Pokemon go a few } \\
\text { times and many years ago. Occasionally I } \\
\text { will use Amazons AR feature to let you see } \\
\text { objects in your room. }\end{array}$ & $\begin{array}{l}\text { I hope to learn some history as I am walking around as } \\
\text { the app gives us a sort of tour of its own. We are able to } \\
\text { explore what we are interested in as we are literally } \\
\text { walking through history. }\end{array}$ & 8 \\
\hline Yes & Yes, briefly played Pokemon Go in 2016. & $\begin{array}{l}\text { I expect to learn more about the copper mine and other } \\
\text { interesting historical artifacts that may be in the app. I } \\
\text { also expect to learn more about AR just by using the } \\
\text { app. }\end{array}$ & 8 \\
\hline No & NA & $\begin{array}{l}\text { How the land is use in changed from the past to the } \\
\text { present }\end{array}$ & 5 \\
\hline Yes & $\begin{array}{l}\text { Minecraft AR app } \\
\text { Google glass demo } \\
\text { Hololens demo }\end{array}$ & Some info about the workers at champion & 8.7 \\
\hline No & & I have no expectations/anticipations. & 7 \\
\hline No & & $\begin{array}{l}\text { I want to learn the applications and possibilities of AR. I } \\
\text { also want to learn from the app and explore a mine } \\
\text { shaft. }\end{array}$ & 10 \\
\hline No & No previous experience & $\begin{array}{l}\text { I think it will be neat to be able to see what used to be } \\
\text { there, when compared to the current day }\end{array}$ & 9 \\
\hline No & NA & $\begin{array}{l}\text { I hope to learn how AR can interact with our } \\
\text { surroundings especially in a historical sence. The } \\
\text { blending of cutting-edge technology and recalling the } \\
\text { past is very interesting to me. Additionally, I hope to } \\
\text { gain insight into the people and places that existed at } \\
\text { the Champion mine during its golden years. }\end{array}$ & 10 \\
\hline Yes & $\begin{array}{l}\text { PokemonGo, primarily, however I have } \\
\text { also utilized apps like Starcharts for } \\
\text { stargazing as well. }\end{array}$ & $\begin{array}{l}\text { I anticipate it being a unique experience for learning } \\
\text { about a historical site while actually being at the site; } \\
\text { being able to see pictures and read about historical } \\
\text { situations while actually being present and being able to } \\
\text { see and feel the location. I'm very excited. }\end{array}$ & 10 \\
\hline No & N/A & $\begin{array}{l}\text { I am excited to learn about how the past landscape } \\
\text { once looked using the the AR application. I think it will } \\
\text { be a great experience and a very convenient one! }\end{array}$ & 10 \\
\hline Yes & $\begin{array}{l}\text { I believe you said video games used this } \\
\text { (Mario Kart and Pokemon Go). I've played } \\
\text { those before. }\end{array}$ & $\begin{array}{l}\text { I think it will be cool to see what the app provides and } \\
\text { learn about the area in the time of its operation. }\end{array}$ & 7 \\
\hline
\end{tabular}




\begin{tabular}{|c|c|c|c|}
\hline No & & $\begin{array}{l}\text { More about the mining history at the visited location in } \\
\text { a more interactive way. }\end{array}$ & 10 \\
\hline No & & $\begin{array}{l}\text { I expect to learn how this new technology can help us } \\
\text { understand historical sites better. }\end{array}$ & 8 \\
\hline Yes & $\begin{array}{l}\text { Played Pokemon GO, and the AR } \\
\text { emojis/bitmojiis on different social } \\
\text { medias }\end{array}$ & $\begin{array}{l}\text { I think it will give a better perspective. Its one thing to } \\
\text { see pictures of a place, its another to actual go and see } \\
\text { something in person. Being able to show things that } \\
\text { used to be somewhere will just help us get a better } \\
\text { picture of what was there. }\end{array}$ & 7 \\
\hline No & & I don't know & 7 \\
\hline No & No prior experience & $\begin{array}{l}\text { I anticipate the use of AR being additive to the } \\
\text { experience of exploring the historical landscape we are } \\
\text { going to visit. I hope to be able to interact with my } \\
\text { surroundings in a way that isn't possible without the use } \\
\text { of technology to hopefully gain different perspectives } \\
\text { on the place that I am visiting. One thing that I am } \\
\text { hoping this experience is not is a distraction; if the use } \\
\text { of technology distracts from my ability to understand } \\
\text { and explore the historical landscape, then I see its use } \\
\text { as an obtrusion on the experience. }\end{array}$ & 8 \\
\hline Yes & $\begin{array}{l}\text { Pokemon go, using depth sensors to map } \\
\text { out a room on }\end{array}$ & History about the copper country I didn't know & 8 \\
\hline No & No. & Some history at the location. & 10 \\
\hline No & I have no experiene & $\begin{array}{l}\text { I hope to learn about how AR can be used to help others } \\
\text { learn about the environment around them. }\end{array}$ & 10 \\
\hline Yes & $\begin{array}{l}\text { I played pokemon go alot during freshman } \\
\text { year as well as the mario kart ar game at } \\
\text { friends houses. }\end{array}$ & $\begin{array}{l}\text { I would love to learn more about the buildings and } \\
\text { history of the architecture around the Keweenaw. }\end{array}$ & 8 \\
\hline Yes & $\begin{array}{l}\text { Pokemon Go } \\
\text { The Nintendo } 3 \mathrm{~d} \text { s had some AR games } \\
\text { although I haven't played them in a very } \\
\text { very long time }\end{array}$ & $\begin{array}{l}\text { About the local area and the history behind it. } \\
\text { About how AR can be used to more effectively learn } \\
\text { about information and history of the area as we are } \\
\text { currently in it. }\end{array}$ & 7 \\
\hline Yes & $\begin{array}{l}\text { I have used basic AR applications in some } \\
\text { games on my phone. }\end{array}$ & $\begin{array}{l}\text { I expect to learn more about the area and what events } \\
\text { took place. }\end{array}$ & 7 \\
\hline Yes & Playing Pokemon Go & $\begin{array}{l}\text { Where buildings used to be located and what they were } \\
\text { used for. }\end{array}$ & 8.5 \\
\hline No & $\mathrm{N} / \mathrm{A}$ & How the equipment works and how it can be useful & 10 \\
\hline
\end{tabular}




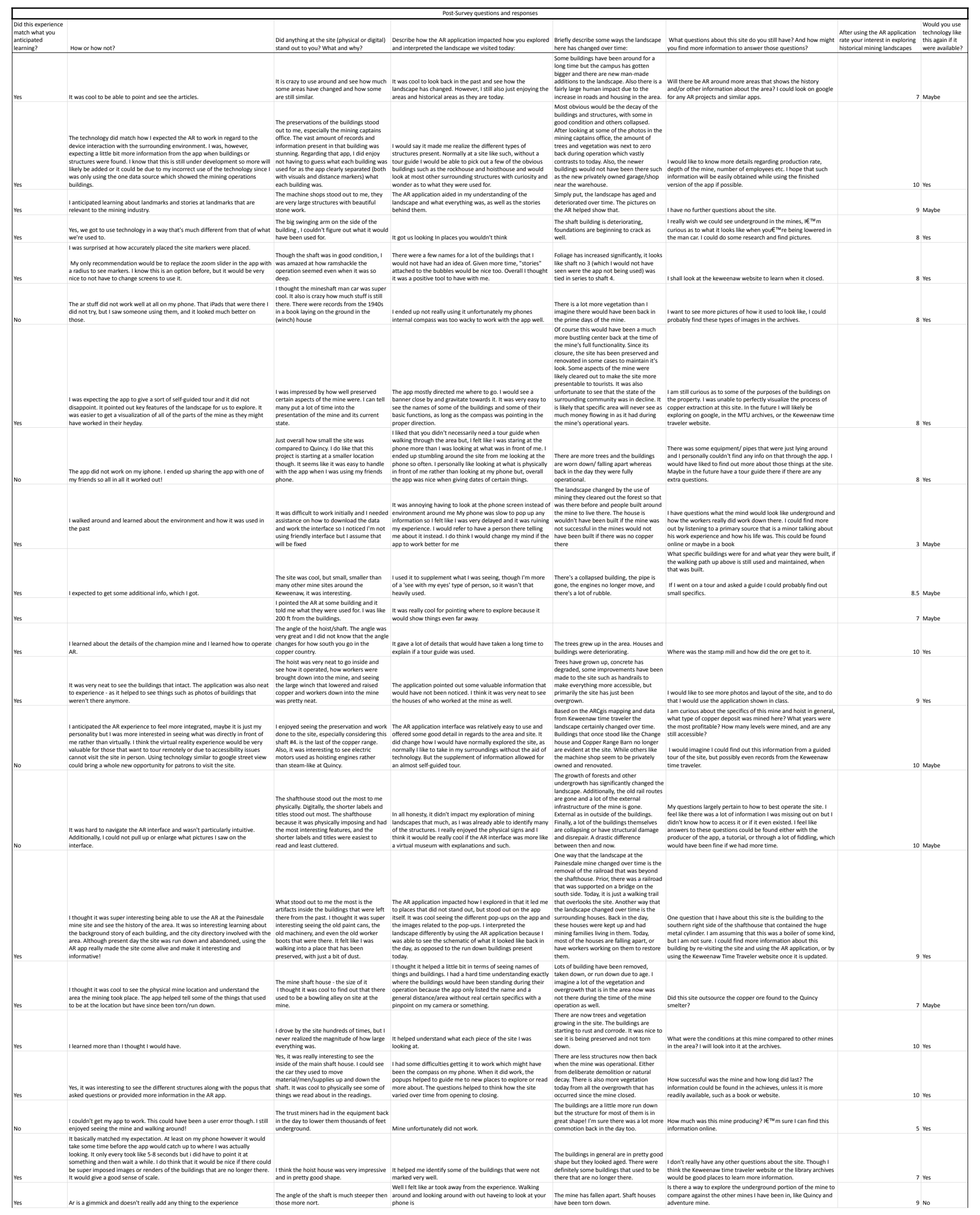




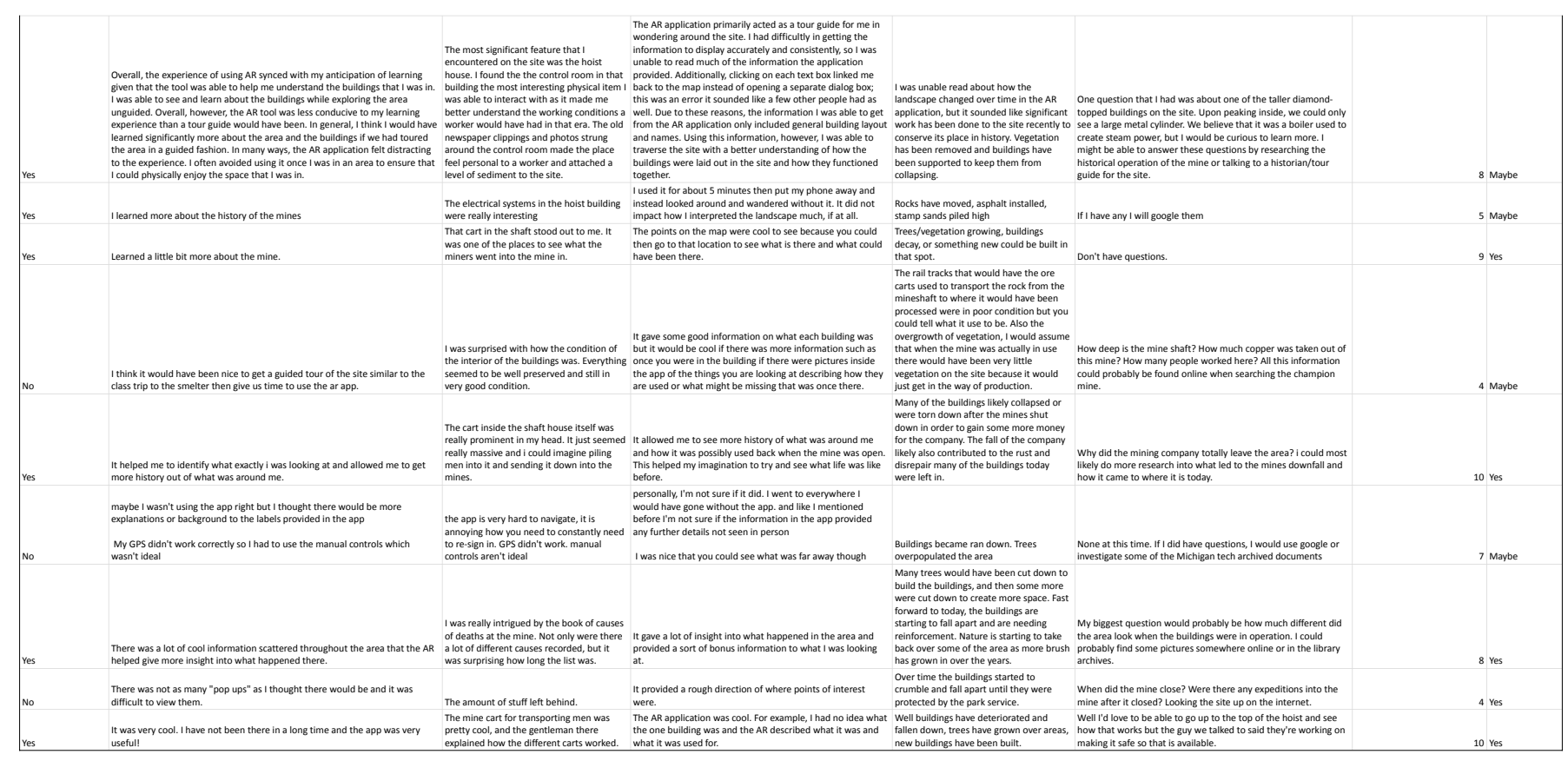

